Rhode Island College

Digital Commons @ RIC

$11-15-2012$

\title{
Gendered Patterns in High Achievement in Mathematics for Grades 4,6, and 8
}

Laura J. Falvey

Rhode Island College

Follow this and additional works at: https://digitalcommons.ric.edu/etd

Part of the Educational Assessment, Evaluation, and Research Commons, and the Science and Mathematics Education Commons

\section{Recommended Citation}

Falvey, Laura J., "Gendered Patterns in High Achievement in Mathematics for Grades 4,6, and 8" (2012). Master's Theses, Dissertations, Graduate Research and Major Papers Overview. 63.

https://digitalcommons.ric.edu/etd/63

This Dissertation is brought to you for free and open access by the Master's Theses, Dissertations, Graduate Research and Major Papers at Digital Commons @ RIC. It has been accepted for inclusion in Master's Theses, Dissertations, Graduate Research and Major Papers Overview by an authorized administrator of Digital Commons @ RIC. For more information, please contact digitalcommons@ric.edu. 
GENDERED PATTERNS IN HIGH ACHIEVEMENT IN MATHEMATICS

FOR GRADES 4, 6, AND 8

BY

LAURA J. FALVEY

A DISSERTATION SUBMITTED IN PARTIAL FULFILLMENT OF THE

REQUIREMENTS FOR THE DEGREE OF

DOCTOR OF PHILOSOPHY

IN

EDUCATION

UNIVERSITY OF RHODE ISLAND

AND

RHODE ISLAND COLLEGE

2012 


\section{DOCTOR OF PHILOSOPHY DISSERTATION}

OF

LAURA J. FALVEY

\section{APPROVED:}

Dissertation Committee:

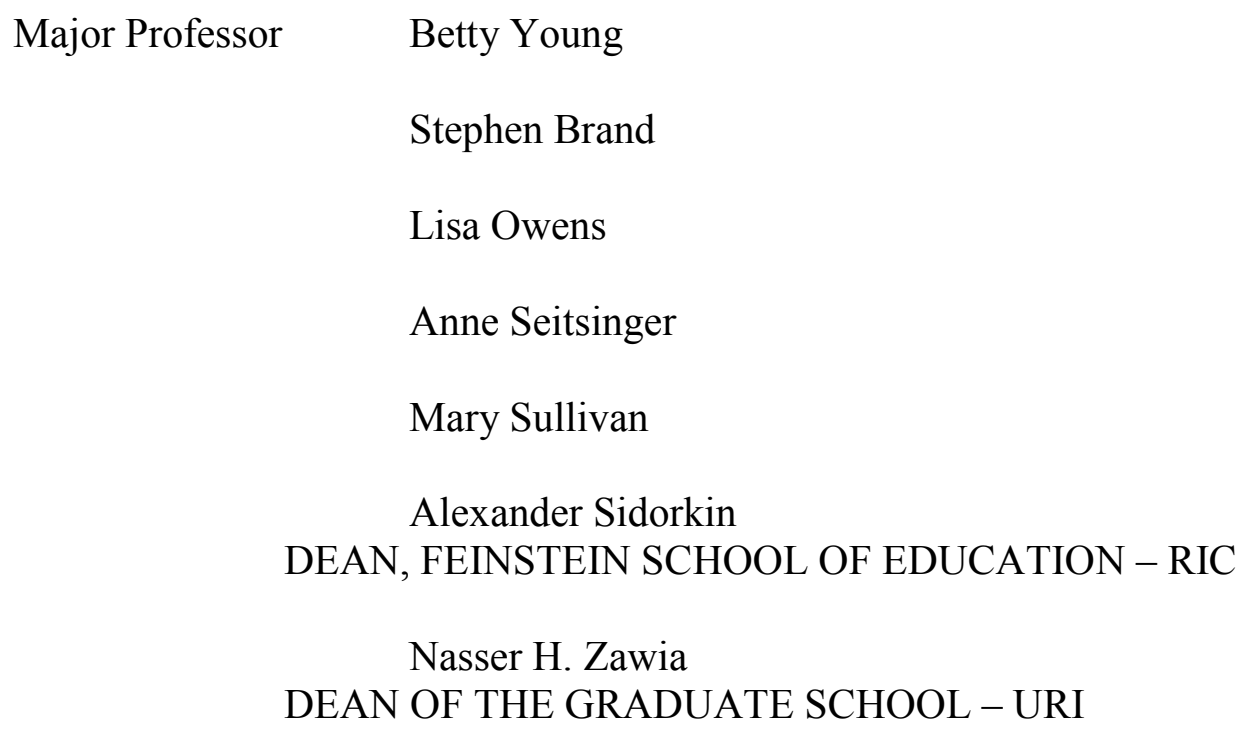

UNIVERSITY OF RHODE ISLAND

AND

RHODE ISLAND COLLEGE 


\begin{abstract}
The issue of underrepresentation of women in science, technology, engineering, and mathematics (STEM) careers is especially important to the future of the United States in current times when STEM careers play an increasingly important role in the global economy (Toulmin \& Groome, 2007; United States Department of Labor, 2007). The pool of students who enter careers in science, technology, engineering, or mathematics first appear in elementary school and overwhelmingly come from those with high achievement in mathematics (Berryman, 1983; Tai, Liu, Maltese, \& Fan, 2006).

This study examined mathematics achievement data for students in grades 4 , 6 , and 8 in one northeastern state to determine whether inequitable patterns exist along gendered lines. This study used quantile regression methodology to examine mathematics achievement as a function of gender and other student characteristics to reveal if differences exist in the top percentiles of achievement densities for this population. The use of a quantile model enabled the capture of any percentile of the distribution to reveal changes by student characteristics, allowing a more precise picture of achievement in mathematics than could be revealed by means-based methods.

Results of the analyses required a rejection of the null hypothesis there is no difference in mathematics achievement by gender in this population. Further, the point advantages and disadvantages revealed are potentially important for both males and females and may reflect impactful patterns of achievement at both the high and low ends of achievement in mathematics. Additionally, patterns of lower mathematics
\end{abstract}


achievement were revealed for students with limited proficiency in English, lower socioeconomic status, and/or membership in a racial minority group. 


\section{ACKNOWLEDGMENTS}

I would like to acknowledge several people who have supported my research journey with their guidance and expertise. First I would like to thank my major professor, Dr. Betty J. Young Lartigaud, who has been unwavering in her support and encouragement through the many stages of this process. I came to know Dr. Young Lartigaud first as my professor, then as my mentor and advocate, and ultimately as a wonderful friend. She saw something in me before I saw it in myself, and for that I am forever grateful. Thanks for the laughter, kindness, and pushes.

I would also like to thank my committee members, Dr. Stephen Brand, Dr. Lisa Owen, Dr. Anne Seitsinger, and Dr. Mary Sullivan. I was fortunate that each of you agreed to bring your distinct voice and specific expertise to this process. Your wisdom and commitment to the subject of mathematics education and children has enriched my journey and I am grateful each of you agreed to accompany me on this long road.

I must also thank Dr. Andrew Penner, who inspired me through his research and allowed me to reach out to him electronically. Your feedback was truly a great assistance.

I am grateful to Dr. Kathleen Kiernan, my friend of 40 years who inspired me and always supported my dream with her wit and wisdom.

A warm thank you to Rouba Youssef, a great source of technical support and now, a new friend.

I would also like to acknowledge the friends who have been in my corner since the beginning and always asked for progress updates while cheering me on. Jill Collins and my aerobic ladies all helped me maintain balance and take it one step at a 
time. Additionally, I am grateful for the cohort women of 2005 who were the exact right people placed in my life at exactly the right time. Sheila McGraw, Laura Chiaravalloti, Jenny Audette, and Janice Place, you've been there for me, helping me stretch as a person and scholar. I am forever grateful to be a part of the power women.

I would also like to acknowledge the state Department of Education for granting access to these data, and thank them for their technical support in preparing the mathematics test score results so that I might pursue this research.

Finally, I would like to acknowledge Dr. Bob Carey. Bob found me years ago teaching in my second grade classroom and recruited me into a Ph.D. classroom. I wish he could be here to see the results. 


\section{DEDICATION}

This work is dedicated to my partner, Timothy Valk, and my son, Alex Falvey

Laliberte. Your love, support, and unfailing faith in me have helped make this possible and I don't thank you enough. Tim, you've kept our home together through the many years of this endeavor and were selfless and uncomplaining. Alex, I treasure your support in both words and actions, and I am so proud that you are my son. 


\section{TABLE OF CONTENTS}

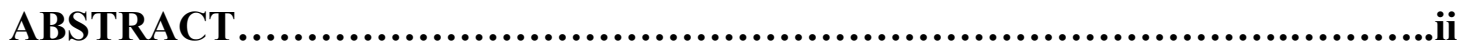

ACKNOWLEDGMENTS ........................................................................................... iv

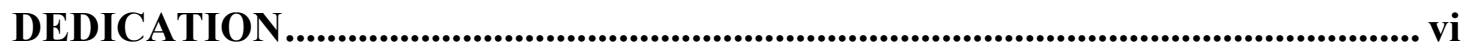

TABLE OF CONTENTS..................................................................................................... vii

LIST OF TABLES .......................................................................................ii

LIST OF FIGURES ............................................................................................................ .

CHAPTER 1: INTRODUCTION AND BACKGROUND.......................................

PURPOSE OF THE STUDY ..................................................5

CHAPTER 2 .................................................................................................................... .7

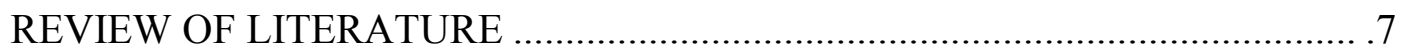

CHAPTER 3 ................................................................................................................... .21

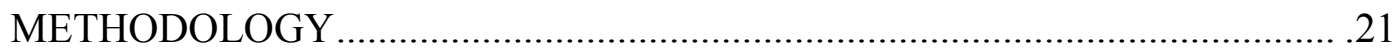

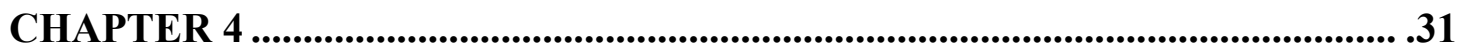

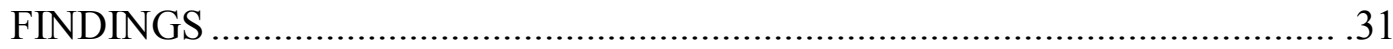

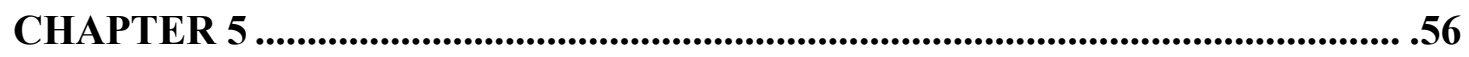

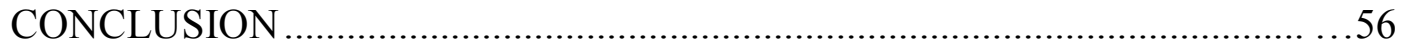

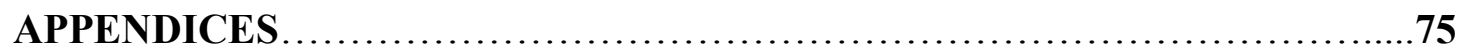

APPENDIX A: DATA REQUEST ......................................... 75

APPENDIX B: DEPTH OF KNOWLEDGE LEVELS ..........................77

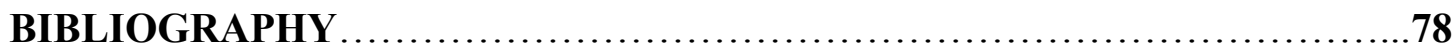




\section{LIST OF TABLES}

TABLE

PAGE

Table 1. Student Population by Grade and Gender 22

Table 2. Number of Students by Free/Reduced Lunch

Participation .23

Table 3. Percentages of Students Identified as Limited English Proficient............24

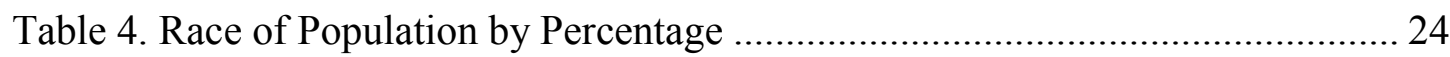

Table 5. Mean Scaled Mathematics Scores...............................................................24

Table 6. Subcategories in Mathematics..........................................25

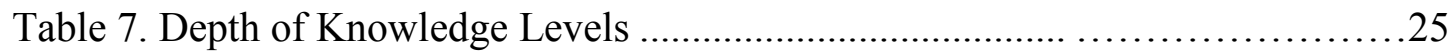

Table 8._Cronbach's Alpha, Standard Error of Measurement in Mathematics.........27

Table 9. Mathematics Scores Means and Standard Deviations by Gender and Grade. 31

Table 10. Analysis of Distribution Skew.........................................33

Table 11. Consequence of Gender on Mathematics Score in Each Quantile............37

Table 12. Achievement Level Cut Scores in Mathematics ............................38

Table 13. Grade 4 Mathematics Score, Gender, and

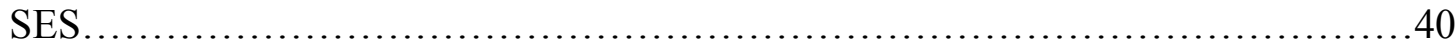

Table 14. Grade 6 Mathematics Score, Gender, and

SES

Table 15. Grade 8 Mathematics Score, Gender, and

SES

Table 16. Grade 4 Mathematics Score, Gender, and

LEP. 
Table 17. Grade 6 Mathematics Score, Gender, and

LEP

Table 18. Grade 8 Mathematics Score, Gender, and

LEP.

Table 19. Grade 4 Mathematics Score, Gender, and

Race.

Table 20. Grade 6 Mathematics Score, Gender, and

Race.

Table 21. Grade 8 Mathematics Score, Gender, and

Race.

Table 22. SES Expected Values and Population Frequencies by Race for Grade 4...51

Table 23. SES Expected Values and Population Frequencies by Race for Grade $6 \ldots .52$

Table 24. SES Expected Values and Population Frequencies by Race for Grade 8 ...53

Table 25. Grade 4 Mathematics Sub-scores by Gender...............................54

Table 26. Grade 6 Mathematics Sub-scores by Gender............................55

Table 27. Grade 8 Mathematics Sub-scores by Gender..........................55

Table 28. Gender and Mathematics Achievement: Grades 4, 6, and 8.....................58 


\section{LIST OF FIGURES}

FIGURE

PAGE

Figure 1. Scaled scores in mathematics for grade 4 students................................. 32

Figure 2. Scaled scores in mathematics for grade 6 students................................ 32

Figure 3. Scaled scores in mathematics for grade 8 students................................ 33

Figure 4. Grade 4 scaled scores in mathematics by female and male test takers with

regression line.

Figure 5. Grade 6 scaled scores in mathematics by female and male test takers with

regression line.

Figure 6. Grade 8 scaled scores in mathematics by female and male test takers with regression line.

Figure 7. The effects of being female on mathematics achievement across the distribution in grades 4,6 , and 8 . 59 


\section{CHAPTER 1}

\section{INTRODUCTION}

\section{Background}

If a democratic education is measured by parity of outcome in achievement and labor force participation, by all reports we have not met the goal of gender equity (Hanna, 2003). Despite recent trends showing increasing parity for females in mathematics achievement (Hyde, Lindberg, Linn, Ellis, \& Williams, 2008; National Center for Education Statistics, 2003a), in the fields of science and mathematics underrepresentation of females persists (Kahveci, Southerland, \& Gilmer, 2006). Males are still more likely to earn their degrees in the lucrative occupations such as physics, computer science, and mathematics (National Center for Educational Statistics, 2004) and in the United States women earn only $19.5 \%$ of all engineering degrees despite representing approximately $56 \%$ of college populations (Kongar, Kontogiorgis, Russo, \& Sobh, 2009).

The issue of underrepresentation of women in science, technology, engineering, and mathematics (STEM) careers is especially important to the future of the United States in current times (United States Department of Labor, 2007) when the concept of a knowledge-intensive economy has a strong hold on governmental thinking (National Science Foundation, 2008). STEM-based occupations play an increasingly prominent role in our global economy (Toulmin \& Groome 2007) and fewer women in these occupations mean fewer thinkers in the STEM talent pool, 
That has been described as a cornerstone of an advanced society and critical to economic competitiveness (National Governor's Association, 2011).

In the summer of 2012, President Obama launched the campaign, Educate to Innovate, with the stated goal of increasing American students' participation in STEM careers (Whitehouse.gov, 2012). Historically the US has been a leading global force both economically and intellectually in these domains, but pundits say this is no longer the case (Jacobs, 2005; Kuenzi, 2006). For the United States to maintain a leadership role, it is believed necessary that the quality and quantity of talented minds choosing STEM education-to-career paths be expanded to include underrepresented groups including females (United States Department of Labor, 2007).

The concept of mathematics' function as a "critical filter" for entrance into college and career was first used by Lucy Sells in 1973, and a body of subsequent research has supported her contention, especially as it relates to STEM pathways. Berryman (1983) found that students with high mathematical achievement in grade 9 show increasing interest in quantitative careers from grades 9-12. In a national study, Astin and Astin (1992) found the most consistent predictor of students' interest in a college science major to be their level of mathematical competency. Dunteman et al. (1979) found that those who chose the hard sciences as a college major (i.e. physical sciences, engineering, mathematics, and life sciences) shared the common denominator of higher mathematics achievement in earlier grades.

The pool of students who enter careers in science, technology, engineering, and mathematics first appear in elementary school and overwhelmingly come from those with high achievement in mathematics (Berryman, 1983; Tai, Liu, Maltese, \& 
Fan, 2006). In their research, Miller \& Kimmel (2010) found mathematics plays an important role in the STEM pathway, and the research of Xie and Shauman (2003) also supports the conclusion that achievement scores in mathematics substantially influence initial enrollment in science and engineering post-secondary programs. Since mathematics achievement acts as a critical filter for the STEM school to career path, and gender equity in participation is a desired goal, the role of gender in mathematics achievement warrants further examination.

Researchers have probed the topic of gender equity in mathematics achievement for decades, adding to a formidable body of literature with findings whose conclusions vary depending on sample, methodology, and student age. A 1989 analysis of 98 research studies determined that up to the age of 10 , either no significant gender differences were found or results favored girls (Friedman 1989). Some research analysis of middle school data favor boys as higher achieving (Halpern \& LaMay, 2000) and some favor girls (Tsai \& Walberg, 1983) especially in the domain of algorithmic mathematics (Hyde, Fennema, \& Lamon, 1990; Seegers \& Boekaerts, 1996).

Schreiber's (2002) analysis of the Third International Mathematics and Science Study (TIMSS) populations found that gender differences favoring boys are persisting in the U.S. despite efforts to equalize outcomes. More recent results available through the Nation's Report Card also show males scoring higher than girls on the National Assessment of Educational Progress [NAEP] in mathematics at ages 13 and 17, but indicate no statistically significant difference at age nine (U.S. Department of Education, 2004). Other analyses of NAEP data conducted by McGraw, Lubienski, 
and Strutchens (2006) for the years 1990-2003 offer a comprehensive picture of NAEP by viewing results longitudinally. These authors found that small but persistent gender gaps favoring males continued across all test years and that these disparities did not get smaller over time, with male advantage greatest for all grade levels tested $\left(4^{\text {th }}, 8^{\text {th }}\right.$, and $\left.12^{\text {th }}\right)$ at the top of the percentile ranks (McGraw, Lubienski, \& Strutchens, 2006). McGraw, Lubienski, and Strutchens (2006) findings are of particular interest to those concerned with women's equal representation in higher-level mathematics.

Though the extant literature surrounding gender difference in mathematics achievement varies across specific studies, there is agreement among many large-scale studies and meta-analyses that, before adolescence, there is no gender difference in mathematics achievement or girls have a slight advantage according to Xie and Shauman (2003). In adolescence, a male advantage appears and increases through high school primarily in specific skill sets such as spatial visualization and quantitative reasoning (Leahy \& Guo, 2001). The literature is also in general agreement that the magnitude of gender differences in mathematics achievement has diminished over time (National Center for Education Statistics, 2003a).

With higher mathematical ability correlated with entrance into STEM careers and continued underrepresentation of women in the STEM pipeline despite increased parity of achievement in mathematics, it seems compelling to examine the extremes of high mathematics achievement data to see if gendered patterns exist at earlier stages of education. Equity in mathematics achievement has important implications for society and unpacking test score data beyond central tendencies offers a promise of adding valuable insight to the discussion. 


\section{Purpose of the Study}

Since 2001, No Child Left Behind (NCLB) legislation has mandated that every state test students' educational progress annually, allowing each state to choose among many different instruments (Hoff, 2008). This demand for educational testing of all students has enabled the growth and availability of raw achievement data for subject areas tested and created an opportunity for a wide range of knowledge discovery. Not all states report testing results disaggregated by gender but in 2008, Hyde, Lindberg, Linn, Ellis, and Williams conducted research on data from 10 states that do. They found the weighted mean achievement scores in mathematics showed no statistical difference between males and females for all tested grades ( 2 through 11) for those states' data (Hyde, Lindberg, Linn, Ellis, \& Williams, 2008). This finding aligns with research showing increasing parity for females in mathematics achievement (National Center for Education Statistics, 2003a).

In the current study, a northeastern state's annual NCLB test results for students in $4^{\text {th }}, 6$ th, and 8 th grades, during the 2010-2011 school year, are the source of data. An examination of mean scores for this population shows no gender differences in mathematics achievement. Reporting achievement results solely based on the statistical mean of test scores potentially overlooks information that other examinations of the distribution may provide especially when the area of interest is high achieving students (Koerselman, 2010). The purpose of this study is to examine extremes in high mathematics achievement testing data to determine whether inequitable patterns exist along gendered lines. The following research questions are be addressed in this research: 
- Are there meaningful differences between males and females in mathematics achievement in grades 4, 6, and 8 at the upper extremes of the distribution?

- How do race, socioeconomic status, and limited proficiency in English intersect with gender at the upper extremes of achievement?

Gender issues surrounding equity in mathematics achievement have important implications for both educational systems and society. Although many elements influence the underrepresentation of women in the STEM pipeline, achievement in mathematics is positively linked to entrance into the fields of science, technology, engineering and mathematics (Steen, 1987; Tai, Liu, Maltese, \& Fan, 2006; Miller \& Kimmel, 2010). By delving deeply into one state's mathematical achievement data, early evidence of concealed but influential disparities in male and female performance in mathematics may be described. This study's goal is to add quantitatively to the conversation about gender and mathematics achievement. By using regression methods to unravel the extremes of achievement data by gender, it is hoped that potentially overlooked inequities will be illuminated, and in time, addressed in curricula and instructional reforms. 


\section{CHAPTER 2}

\section{REVIEW OF LITERATURE}

Gender differences in mathematics achievement have been a topic of interest for educational stakeholders for decades, having a long history of qualitative and quantitative analysis. In this chapter, relevant literature is examined in three consequential areas. The first section looks at the history of gender and education. Following this, important research surrounding male and female differences in mathematics achievement is examined. The third section examines studies in which the intersections of gender, race, and socioeconomic status have been considered.

Gender and Education

\section{History}

Early research literature surrounding gender in education focused primarily on describing differences between the sexes. Anatomical proportions, physical, emotional, and/or intellectual processes of males and females were compared from various points of view. With the advent of formal psychology (generally accepted to be around 1879), researchers began using scientific methods to examine human development and individual differences including gender, with females being considered in relation to Caucasian males (Shields, 1975; Milar, 2000).

In the late $19^{\text {th }}$ and early $20^{\text {th }}$ century, the ideas of evolutionary theory dominated scientific thinking and the importance of variability in biology provided the foundation for researching the "inborn" differences in the nature of each gender 
(Hyde, 1990). Charles Darwin's cousin, Francis Galton, researched men and women's intellectual differences and reported in 1907 that women were found to be inferior to men in every way (in Hyde, 1990). In 1910, Helen Thompson Woolley was the first of her time to conduct a review of past research on psychological differences between men and women and famously wrote, "There is perhaps no field aspiring to be scientific where flagrant personal bias, logic martyred in the cause of supporting a prejudice, unfounded assertions, and even sentimental rot and drivel, have run riot to such an extent as here. (p. 340)"

Woolley (then named Thompson) was one of the first researchers to conduct systemic scientific investigation on gender differences in performance when she produced her 1903 study The Mental Traits of the Sexes (Halpern et al., 2007). Thompson compared 25 men and 25 women on a variety of motor, sensory, and cognitive tasks, and described the complete distribution of the scores in her results, rather than mean performance alone (Milar, 2000). In her conclusions, Thompson challenges her predecessors' evolutionary explanations of differences and instead points to the social and environmental influences affecting males and females from infancy to adulthood (Thompson, 1903).

Researchers' interest in gender differences in the decades to follow varied, with the exception being developmental psychologists who focused more continually on gender as a variable than those in other disciplines (Jacklin, 1989). In 1974, Maccoby and Jacklin evaluated over 1,400 references on sex differences in their oftcited work, The Psychology of Sex Differences. The authors, summarizing a vast amount of research, found four specific areas of sex differences; visual-spatial 
perception, aggression, and mathematics ability all which favored males, and verbal ability, which favored females (Emmons \& Jacklin, 1974). Maccoby and Jacklin dispelled many common perceptions about gender differences and pointed to the critical need for further research (Maccoby \& Jacklin, 1974).

Through the 1960's and continuing into the 1970's, much of the research concerning gender was focused on deficits in males, primarily related to behaviors and academic performance (Sadker, Sadker, \& Klein, 1991). Among these earliest topics were boys' inferior performances in reading, lower verbal abilities when compared to girls, (Dwyer, 1973; Leinhardt, Seewald, \& Engel, 1979; Klein et al., 1994) and higher rates of grade level retention (Abidin, 1971; Sadker, Sadker, \& Klein, 1991).

At the same time feminists were opening the door to a dialogue about sex-role biases with widespread consequences. Originating in unequal opportunities for women in economic, cultural, political, and social settings, the "feminist focus" extended logically into education and its role in subordinating females (Tyack \& Hansot, 1992). This dialogue, concerned with inequality, brought into question the treatment of females at all levels of education, but especially in relation to equal access to learning and employment opportunities (Klein et al., 1994).

The social movement of feminism and its emphasis of unequal treatment of women was the impetus for government legislation, perhaps the most far-reaching related to education being the 1972 passage of Title IX. This legislation was a defining moment in the history of gender and equality in education since, for the first time, discrimination based on sex was prohibited in federally assisted educational programs (Tetreault, 1986). Although Title IX provided a legal tool to combat explicit gender 
bias in schools, actual results of the legislation were perhaps best described by the National Advisory Council on Women's Educational Program's report titled Title IX: The Half Full, Half Empty Glass (1981). The Council documented institutional changes resulting from Title IX benefiting both genders but clearly noted the distance not yet spanned to fulfill the goals of the legislation (National Advisory Council on Women's Educational Programs, 1981).

The feminist movement's focus on equal opportunities for women put the spotlight on achieving equitable outcomes in education, influencing a growing body of research. Among the researched topics during the 1970's and 80's were the subtle patterns of bias in classroom interaction involving teacher-student dynamics (Eccles \& Blumenfeld, 1985; Sadker, Sadker, \& Klein, 1991) and included the teaching of math and science (Hanna, 2003). During this time period, classroom emphasis was on direct instruction of students and, viewed through a lens of gender equity, numerous studies documented the different treatment of students that penalized female students (Good, 1981; Prawat \& Jarvis, 1980; Sadker, Sadker, \& Klein, 1991). Discrepancies in teacher interactions were found to include more frequent dialogue with males (Jones, 1989), more complex questions directed at boys (Sadker \&Sadker, 1990; Meece, Glienke, \& Burg, 2006), and more precise praise or criticism for correct or incorrect answers for male students (Becker, 1981).

The gender dialogue continued in the 1990's, bringing with it numerous publications and books focused on the disadvantages of being female in U.S. public schools. The American Association of University Women [AAUW] published How Schools Shortchange Girls highlighting the ways in which curricula and teaching 
methodology, especially in the sciences and mathematics, deprive female students of equal opportunities (AAUW, 1992). Peggy Ornstein's SchoolGirls (1994) included discussion of girls' achievement gaps in math and science and their unequal treatment at the hands of teachers. Throughout the decade, researchers continued to probe the topic of gender, equity, and education, adding to a formidable body of literature (Schrieber, 2002).

Among the effects of gender and equity discussions were a 1990's resurgence of interest in the lived experiences of boys in and out of the classroom. Authors such as Pollack (1998), who debunked stereotypical myths about boys, and Gurian (1998), who wrote about the biological nature of males and their inherent strengths and vulnerabilities, served to stimulate this decade's often contentious dialogue about gender equity for both sexes. Christian Hoff Sommers in The War Against Boys (2000) called boys the weakest side of the gender gap and argued that schools disadvantage males. Kindlon and Thompson (1999) wrote of the feminine environment of schools and the negative consequences of early expectations surrounding reading and writing for active, average boys. As a result, the feminist focus on disparity of educational outcome for girls was broadened to make a case for the inequality of boys' achievement in reading and writing (Weaver-Hightower, 2003). Pollack, Kindlon, Gurian and others raised issues that have lingered into the $21^{\text {st }}$ century about equity and children, and the power of education to support the success or failure for both genders. 


\section{Gender and Mathematics}

"Boys are better at math than girls." While conventional belief often holds that boys outperform girls in mathematics, research findings vary and can conflict, depending on population, measurement, and purpose (Friedman, 1989; Schrieber, 2002). The complexities of factors influencing boys' and girls' mathematics achievement require researchers to choose a narrow slice from among a broad array of possible study foci. Each research "slice" has contributed to the large body of extant literature and has included student factors such as boys' and girls' self-judgments, motivations, attributions, socialization, and strategy choices.

One of the many lenses for examining gender differences in mathematics achievement include male and female personal belief systems in relation to academic outcome. In a qualitative study investigating gender differences and motivation, Vermeer, Boekaerts and Seegers (2000) considered task-specific behaviors surrounding the solving of math problems. Researchers found gender differences occurring in student attitude and motivation, with girls judging themselves as having lower competence when compared to boys' self-judgments (Vermeer, Boekaerts, \& Seegers, 2000). Fennema and Sherman's $(1977,1978)$ findings also supported boys' higher confidence about their ability in mathematics, even in cases where no evidence of superior achievement was found. Other researchers have pointed to higher male competitiveness during mathematics tasks with females' lower competitiveness but greater willingness to invest effort in mathematics (Seegers \& Boekaerts, 2000).

Attribution theorists such as Bernard Weiner have shown there are personal attributions correlated with academic success (1986). Research showing boys as more 
likely to attribute failure in mathematics to luck and girls as more likely to attribute failure to low ability may indicate a pattern with consequences for girls' mathematical performance (Stipek \& Gralinski, 1991). In 1993 psychologist Albert Bandura used the term self-efficacy to describe a person's judgment about whether a particular activity is doable, and linked higher self-efficacy to greater effort and persistence on difficult tasks, correlating with greater success. Boys' and girls' judgment about whether they can or cannot succeed in mathematical problem solving is a student factor positively related to achievement (Martin \& Marsh, 2006; Seigel \& McCoach, 2007).

Facets of boys' and girls' socialization have been considered as contributing to gender differences in mathematics achievement with mixed results. If girls learn from parents, teachers, and society that the field of mathematics is "male" territory, then this could become self-fulfilling, negatively impacting girls' interest and willingness to attempt mathematics (Fennema \& Sherman, 1978). Felson and Trudeau (1991) found no evidence that standard socialization explains gender differences, but did find girls experiencing more anxiety about mathematics.

Boys may have a socialization advantage described as the neighborhood effect. Since boys traditionally are allowed more freedom to explore their neighborhoods, play unsupervised sports, and develop complex outdoor games, this factor may contribute to boys' advantaged spatial skills and numerical ability (Entwisle, Alexander \& Olson, 1994). When situationally possible, boys were found to have more frequent experiences out of the house than girls with the exception of 
disadvantaged boys living in neighborhoods with high crime and poverty (Entwisle, Alexander \& Olson, 1994).

Strategy-based differences have been found in girls' and boys' approaches to mathematics with achievement consequences. In a longitudinal study of students in grades 1-3, Fennema, Carpenter, Jacobs, Franke, and Levi (1998) found compelling evidence that boys and girls approach mathematics with different strategies and that these differences can be defined by gender. In the research conducted by Fennema, and her colleagues (1998), results showed girls using significantly more standard algorithms while boys used more invented methods to solve the same problems. Following standard procedures in mathematical problem solving has been correlated with shallow conceptual understanding while invented strategies have been positively related to achievement in mathematics (Fuson et al., 1997). Findings from research indicate standard algorithms represent a simple, surface approach to a problem, while invented methods require deeper, more flexible knowledge activation (Lowrie \& Kay, 2001; Silver \& Thompson, 1984), and Fennema et al., (1998) posited that girls' more frequent reliance on standard procedures might presage their later lower achievement scores.

Gender and Mathematics at the High, Middle, and Elementary School Levels

Numerous studies have looked at mathematics achievement in middle and high school students, perhaps due to the large-scale availability of quantitative information in the form of achievement test scores (Leahy \& Guo, 2001). During students' middle school years, some research found no gender differences (Hall, Davis, Bolen \& Chia, 1999), some data favor boys as higher achieving (Halperen \& LaMay, 2000) and some 
favor girls (Tsai \& Walberg, 1983) especially in the domain of algorithmic mathematics (Hyde, Fennema, \& Lamon, 1990; Seegers \& Boekaerts, 1996).

Friedman (1989) examined 98 research studies and concluded that up to age 10 either no significant gender differences were found or the results favored girls. Schrieber's analysis of the Third International Mathematics and Science Study (TIMSS) test results for grades 4,8 , and the last year of secondary school found that gender differences favoring boys are persisting despite efforts to equalize outcomes (2002). More recent results available through the Nation's Report Card also show males scoring higher than girls on NAEP assessments in mathematics at ages 13 and 17, but indicate no statistically significant difference at age nine (U.S. Department of Education, 2004).

The answer to when gender differences initially appear varies and has spanned all school ages in researchers' conclusions. Some research indicates by first grade (Geary, Saults, Liu, \& Hoard, 2000), others by age 12 (Benbow, 1988), and others report not until adolescence are differences evident (Hyde, Fennema \& Lamon, 1990).

McGraw, Lubienski, and Strutchens (2006) analyzed NAEP data for the years 1990-2003 and found small but persistent gender gaps favoring males continuing across all test years with disparities not getting smaller over time. Male advantage was greatest for all grade levels tested $\left(4^{\text {th }}, 8^{\text {th }}\right.$, and $\left.12^{\text {th }}\right)$ at the top of the percentile ranks, indicating significantly more males scored at advanced achievement levels

Using five testing years from the large nationally representative data set National Longitudinal Survey of Youth [NLSY] $(1986,1988,1990,1992,1994)$, Leahy and Guo (2001) found mean scores for mathematics achievement varied little 
by gender until age 11. Penner and Paret (2008) examined data from the Early Childhood Longitudinal Study, Kindergarten Class of 1998-99 longitudinally from Kindergarten through fifth grade. In contrast to those reporting no gender differences in mathematics achievement in the early grades (U.S. Department of Education, 2004), Penner and Paret (2008) looked at the high and low achieving tails of the data and revealed a female disadvantage in the highest achieving students as early as spring of Kindergarten year which became larger in the ensuing grades. The authors posited that the extreme ends of achievement performance are of more interest when discussing gender in mathematics and that basic descriptive statistics' use of mean and variances may veil important information about gender (Penner \& Paret, 2008). Their findings suggest that males enter kindergarten already mathematically advantaged at the top of the distribution.

Socioeconomic Status, Race, and Mathematics Achievement

\section{Socioeconomic Status and Achievement}

The socioeconomic status (SES) of a child has long been considered a factor affecting that student's academic achievement and been perhaps the most widely used situational variable when educational research has focused on achievement (Sirin, 2005). The methods of defining SES have varied across research studies and included family financial status, level of parental education, as well as parental career status. The unit of analysis of socioeconomic status has ranged from individual students, schools, to neighborhoods.

Karl R. White conducted the first meta-analysis of research surrounding SES and educational achievement in 1982. White (1982) found an inconsistent range of 
correlations between SES and achievement when he examined approximately 200 studies. Using meta-analytic statistical techniques quantifying results across the literature, White (1982) reported a relatively weak correlation $(r=0.22)$ between achievement and socioeconomic status, although when measures of family characteristics describing home environment were included in the analysis, correlation more than doubled.

In 2005, Selcuk Sirin reviewed literature focusing on socioeconomic status and achievement from 1990 to 2000 . His meta-analysis included 101,157 students and found a correlation between measures of student achievement and socioeconomic status at the $r=0.29$ level. Sirin (2005) reported that free or reduced lunch status was the most frequently used measure of socioeconomic status.

Eligibility for free or reduced lunch status is based upon family income guidelines set at the national level. Those families who earn at or below $130 \%$ of the poverty level are eligible for free lunch while those with incomes between $130 \%$ and $185 \%$ of the poverty level are eligible for reduced price lunches (U.S.D.A., 2012). For a family of four in the year 2010 , this translated to an annual income of $\$ 28,665$ for free lunch eligibility, and a maximum annual income of $\$ 40,793$ for reduced price lunch eligibility (U.S.D.A., 2012). Although this has been criticized as being a gross measure which does not take into consideration other important factors, eligibility for free or reduced lunch is readily available public data as these statistics are reported to state and federal agencies. There is some evidence that the effect of SES by this measure is weaker in upper grades than lower, perhaps because the paperwork that 
families are required to complete in order to qualify for free lunch is less likely to be transmitted by adolescents (McLoyd, 1998).

McGraw, Lubienski, and Strutchens (2006) conducted research that included analysis of achievement in mathematics as measured by NAEP and considered socioeconomic status and gender among factors. By examining scores of fourth, eighth, and twelfth grade students, results revealed that students with higher SES had greater gender gaps in achievement, which favored males, than their less advantaged

peers (McGraw, Lubienski, \& Strutchens, 2006). Helen Ladd (2012) recently analyzed data from six administrations of the NAEP testing of grades 4 and 8 considering the effects of poverty on achievement. Ladd concluded in her results that poverty negatively effects student achievement, especially in the area of mathematics.

\section{Race and Achievement}

Teasing out the factors of race and socioeconomic interactions with mathematics achievement is an evolving research challenge for those concerned with equity in education. The interplay of race and educational achievement is complex and difficult to untangle from other factors such as socioeconomic status, school composition, and proficiency in English. Especially in the early grades when neighborhoods determine school enrollment, schools are more likely to be separated by social factors and there is less variation of socioeconomic status (Entwisle \& Alexander, 1993).

The racial balance of a school has been associated with differences in mathematics achievement and some results indicate that when a school has $50 \%$ or more Black and Hispanic students, all students have lower achievement (Brown-Jeffy, 
2009). Black and Hispanic students are more likely than White students to be situated within urban schools with high poverty, and students in these lower income schools perform consistently lower (Darling-Hammond, 2010). Further complicating the issue of race and achievement are research findings that reveal those schools with more minority students and greater poverty are more likely to have less qualified teachers (Lankford, Loeb, \& Wyckoff, 2002) and be systemically underfunded (DarlingHammond, 2010).

The correlation of race and achievement in mathematics has been documented in many quantitative studies. NAEP results are a source of quantitative data disaggregated by race and have frequently been a source for research surrounding mathematics achievement. Lubienski and Lubienski (2006) reviewed 2003 NAEP scores for grades 4 and 8 considering both student and school characteristics. Among their findings were gaps of 15.8-points for Black students, 6.5 for Hispanic students, and 4.2 for American Indian students on mathematics tests when compared with White peers, even when SES was similar (Lubienski \& Lubienski, 2006). A 2009 examination of NAEP results for mathematics achievement revealed a troubling pattern of Black and Hispanic students lagging behind White peers since the inception of NAEP testing (Brown-Jeffy, 2009). In Hemphill and Vanneman's 2011 report on NAEP results, Hispanic and White students' achievement on the mathematics portion of the NAEP test was compared over time. They found a 19-point gap in fourth grade scores of Hispanic students in 1990 that was not statistically different from the 21point gap revealed in 2009 (Hemphill \& Vanneman, 2011). Eighth graders who are 
Hispanic also maintained a gap between those years; in 1990 a 24-point gap and in 2009 a 26-point gap (Hemphill \& Vanneman, 2011).

The interplay of poverty, proficiency in English, school environment, and teacher quality are all parts of the mosaic that intersect with race as cofactors affecting achievement (Brown-Jeffy, 2009). Although understandings of the relationships among the specific mechanisms at work are evolving with research, there exists a general consensus in the literature that students' socioeconomic status and racial identity continue to be factors in mathematics achievement (Jacobs, 2005). 


\section{CHAPTER 3}

\section{METHODOLOGY}

\section{Overview of the Study}

This study uses quantile regression methodology to examine mathematics achievement as a function of gender and other student characteristics to reveal if differences exist in the top percentiles of achievement densities for this population. The use of a quantile model enables the capture of any quantile, or percentile, of the distribution to reveal changes by student characteristics, allowing a truer picture of achievement in mathematics than could be revealed by means-based methods. The goal of this research is to provide an analysis of the phenomenon of gender difference in the highest levels of mathematics achievement.

\section{Student Data}

The data for this study are student achievement scores in mathematics for all public school students in grades 4,6 , and 8 in one northeastern state, provided by that state's department of education. Total size of the population is 31,858 is shown in

Table 1 . The test used by the state is also currently used annually by three other states. The test was designed through those states' collaboration to meet federal No Child Left Behind (NCLB) requirements for measuring student achievement in content areas that include mathematics. Nationally recognized measurement and test experts along with local educators ensure the integrity of the tests according to the state's technical report. Guidelines for test scheduling, test administration, and test security are 
provided to all participating school districts and compliance is mandatory.

Table 1

Student Population by Grade and Gender

\begin{tabular}{c|cccr}
\hline Grade & Males & Females & $\begin{array}{c}\text { No Gender } \\
\text { Reported }\end{array}$ & Total $(\boldsymbol{N = 3 1 , 8 5 8 )}$ \\
\hline 4 & 5656 & 5229 & 3 & 10,888 \\
6 & 5184 & 4758 & 2 & 9,944 \\
8 & 5742 & 5279 & 5 & 11,026 \\
\hline
\end{tabular}

The student achievement test results comprising the research data are based on the "Grade Level Expectations" from the prior year. Therefore, analysis of student results for grades 4, 6, and 8 who took the mathematics achievement test in October of 2010 is intended to reveal learning from the prior year, what was learned in 20092010 when these students were in grades 3,5 , and 7 , respectively. A total of 31,858 students are in the population. Ten students were missing a code for gender and their results are omitted based on the gender focus of this study. Student achievement for these grade levels was chosen as the focus of research interest to reveal if results in these grades indicate patterns of interest to those concerned with females' underrepresentation in higher level mathematics and paths to STEM careers.

Research practices were followed in accordance with the University's Institutional Review Board on Human Subjects (IRB). To protect the human subjects of this study and present minimal risk to population members, identifiers linked to the subjects such as school and community names were removed and subject names were replaced with state assigned student identification numbers. This study was exempted from informed consent of student and parent due to the existence of a dataset with no individual or school identifiers. Upon taking physical possession of the data in 
compact disc format, all data safety-monitoring procedures were followed to insure the safety of participants and the validity of data. When not in use, data was stored in a locked university facility. Research analysis was conducted during the spring and summer of 2012.

\section{General Characteristics of the Population}

In the state from which the data originate, the median household income in 2009 was $\$ 53,243$, while $12 \%$ of the population lived below the poverty level and $20.5 \%$ of students over the age of five had a language other than English spoken at home (U.S. Census Bureau, 2010). Statewide, $76.4 \%$ of the population describes itself as White and not Hispanic, 12\% as Hispanic or Latino, 5.7\% as Black, and 2.9\% as Asian (U.S. Census Bureau, 2010). There are a total of 36 school districts in the state and all are represented in the data.

Specific data about socioeconomic status (as measured by free or reduced lunch), limiting proficiency with English (LEP), and race in this population are shown in Tables 2, 3, and 4 respectively. Mean scale achievement scores for grades 4, 6, and 8 show no statistically significant difference and are represented in Table 5.

Table 2

Number of Students by Free/Reduced Lunch Participation

\begin{tabular}{ccc}
\hline & \multicolumn{2}{c}{ Students } \\
Grade & SES O & SES 1 \\
\hline 4 & 5820 & 5068 \\
6 & 5542 & 4392 \\
8 & 6331 & 4695 \\
\hline
\end{tabular}

SES $0=$ no free/reduced lunch, SES $1=$ qualifies for either free/reduced lunch 
Table 3

Percentages of Students Identified as Limited English Proficient (LEP)

\begin{tabular}{ccccc}
\hline Grade & LEP 0 & LEP 1 & LEP 2 & LEP 3 \\
\hline 4 & 91.9 & 6.4 & 1.5 & 0.2 \\
6 & 95.1 & 3.7 & 0.9 & 0.2 \\
8 & 96.2 & 3.2 & 0.3 & 0.3 \\
\hline
\end{tabular}

Note: Code for students not receiving LEP services is LEP 0 , year one of services is LEP 1, monitored status, year two is LEP 2 , monitored status year three is LEP 3.

Table 4

Race of Population by Percentage

\begin{tabular}{c|c|c|c|c|c|c|c|c}
\hline Grade & $\begin{array}{c}\text { American } \\
\text { Indian, } \\
\text { Alaskan } \\
\text { Native }\end{array}$ & Asian & $\begin{array}{c}\text { Black, } \\
\text { African } \\
\text { American }\end{array}$ & $\begin{array}{c}\text { Hispanic, } \\
\text { Latino }\end{array}$ & $\begin{array}{c}\text { Native } \\
\text { Hawaiian, } \\
\text { Pacific } \\
\text { Islander }\end{array}$ & White & $\begin{array}{c}\text { Two or } \\
\text { More } \\
\text { Races }\end{array}$ & $\begin{array}{c}\text { No } \\
\text { Identity }\end{array}$ \\
\hline 4 & 0.7 & 3.1 & 7.8 & 21.7 & 0.1 & 63.6 & 2.6 & 0.5 \\
6 & 0.8 & 3.0 & 7.8 & 19.7 & 0.1 & 65.7 & 2.4 & 0.5 \\
8 & 0.1 & 3.1 & 7.5 & 20.1 & 0.1 & 65.6 & 2.4 & 0.6 \\
\hline
\end{tabular}

Table 5

Mean Scaled Mathematics Scores

\begin{tabular}{cccc}
\hline Grade & Total Population $\mu$ & Male $\mu$ & Female $\mu$ \\
\hline 4 & 443 & 443 & 444 \\
6 & 642 & 642 & 642 \\
8 & 841 & 841 & 841 \\
\hline
\end{tabular}

\section{Instrumentation}

The mathematics test consists of multiple choice, short answer, and constructed response items. Within mathematics, four subcategories are reported:

Numbers and Operations, Geometry and Measurement, Functions and Algebra, and Data, Statistics, and Probability. Table 6 shows the percentage of emphasis for each subcategory. 
Table 6

Subcategories in Mathematics

\begin{tabular}{l|ccc}
\hline Subcategory & Testing grade 4 & Testing grade 6 & Testing grade 8 \\
\hline $\begin{array}{l}\text { Numbers and } \\
\text { operations }\end{array}$ & $50 \%$ & $40 \%$ & $20 \%$ \\
\hline $\begin{array}{l}\text { Geometry and } \\
\text { measurement }\end{array}$ & $20 \%$ & $25 \%$ & $25 \%$ \\
\hline $\begin{array}{l}\text { Functions and } \\
\text { probability }\end{array}$ & $15 \%$ & $20 \%$ & $40 \%$ \\
\hline Data and statistics & $15 \%$ & $15 \%$ & $15 \%$ \\
\hline Total & $100 \%$ & $100 \%$ & $100 \%$
\end{tabular}

Note. Adapted from "New England Common Assessment Program, 2010-2011, Technical Report" Reliability and Standard Errors of Measurement, p.9. Retrieved October 28, 2011 from

http://www.education.nh.gov/instruction/assessment/necap/documents/techrpt july2011.pdf

Depth of knowledge (DOK) levels are assigned to each item based upon the complexity of mental processing a student must use to solve a problem, from level one being the most simple to level 3, requiring complex problem solving. (See Appendix B for complete definitions). The targeted DOK percentages are shown in Table 7.

Table 7

Depth of Knowledge Levels

\begin{tabular}{cccc}
\hline DOK & Grade 4 & Grade 6 & Grade 8 \\
\hline Level 1 & $22 \%$ & $26 \%$ & $29 \%$ \\
Level 2 & $71 \%$ & $64 \%$ & $62 \%$ \\
Level 3 & $8 \%$ & $11 \%$ & $9 \%$ \\
\hline
\end{tabular}

Note. Adapted from “New England Common Assessment Program, 2010-2011, Technical Report" Reliability and Standard Errors of Measurement, p.10. Retrieved October 28, 2011 from

http://www.education.nh.gov/instruction/assessment/necap/documents/techrpt_july2011.pdf

According to the state agency, mathematics sub-scores cannot be directly compared from one year to the next, even within a grade (New Hampshire Department of Education, 2011). Sub-scores are reported as raw scores and have not been linked across years and placed on the same scale and so only individual student total scaled scores were calculated in this study although raw scores were also supplied by the state agency. Raw achievement scores, or total number of points, are transferred to scaled scores using a data analysis process called scaling. 
For the purpose of this study, scaled scores, as standard scores are the most suitable statistic since they allow for comparisons in student performance across grade levels to the extent that the percentage of students reaching proficiency can be compared. The scaled scores are simple linear transformations of the underlying raw score and do not change a student's achievement level classification according to the testing agency (New Hampshire Department of Education, 2011). To ensure that scaled scores accurately represent students' raw scores, a test of correlation using Pearson's correlation coefficient was performed. Two variables are said to be "correlated" if knowing scores for one helps to predict scores for the other. A correlation coefficient shows the strength of the relationship with a value of zero being no relationship and a value of one indicating a perfect relationship. Correlation between raw mathematics scores and scaled mathematics scores for this population was $r=0.98$ indicating a strong correlation and supporting the decision to use scaled scores as valid.

According to test information posted on the state's website, both qualitative and quantitative analyses are used to ensure the state test meets the standards established in the Standards for Educational and Psychological Testing (AERA et al., 1999) and Code of Fair Testing Practices in Education (2004). Cronbach's alpha is a widely known assessment of reliability to determine the internal consistency or average correlation of items in an instrument to gauge reliability (Duhachek, Coughlan, \& Iacobucci, 2005). Cronbach's (1951) alpha was used by the test makers to compare individual item variances to total test variance and is defined as the following equation: 


$$
\begin{aligned}
& \qquad \alpha \equiv \frac{n}{n-1}\left[1-\frac{\sum_{i=1}^{n} \sigma_{\left(Y_{i}\right)}^{2}}{\sigma_{x}^{2}}\right] \\
& \text { where } \\
& i \text { indexes the item, } \\
& n \text { is the total number of items, } \\
& \sigma_{\left(Y_{i}\right)}^{2} \text { represents individual item variance, and } \\
& \sigma_{x}^{2} \text { represents the total test variance. }
\end{aligned}
$$

Table 8 presents descriptive statistics, Cronbach's alpha coefficient, and raw score standard errors of measurement (SEMs) for grades 4,6 , and 8 in mathematics. According to Nunnaly and Bernstein, higher values of alpha are more desirable and a conventional threshold requires a reliability of 0.70 or higher, although for measures of academic achievement, a reliability of 0.90 or higher is preferred (as cited in Duhachek, Coughlan, \& Iacobucci, 2005). By this standard, the alpha levels at greater than or equal to 0.92 exceed the standard indicating reliability.

Table 8

Cronbach's Alpha, Standard Error of Measurement (SEM), in Mathematics

\begin{tabular}{ccccccc}
\hline Grade & $\begin{array}{c}\text { Number of } \\
\text { students* }\end{array}$ & Maximum & Mean & $\begin{array}{c}\text { Standard } \\
\text { deviation }\end{array}$ & Alpha & SEM \\
\hline 4 & 44350 & 65 & 41.67 & 12.08 & 0.92 & 3.39 \\
6 & 44477 & 66 & 35.16 & 14.52 & 0.93 & 3.94 \\
8 & 46567 & 65 & 31.29 & 13.88 & 0.93 & 3.72 \\
\hline
\end{tabular}

Note. Adapted from "New England Common Assessment Program, 2010-2011, Technical Report" Reliability and Standard Errors of Measurement, p.57. Retrieved October 28, 2011 from http://www.ride.ri.gov/assessment/DOCS/NECAP/Reports_Results/2010-11_NECAP_Math-Reading-Writing_Tech_Report.pdf *Represents the overall student population taking the test.

All items on the mathematics test were calibrated using item response theory (IRT) that describes a relationship between student performance and the probability of getting a multiple choice item correct, or of getting a particular score on an open response item (Baker, 2001). The correlation between student performance on a single item and the total test score is a commonly used measure of an item's discrimination. 
Examination of correlation reveals if a test item successfully discriminates between high and low scores on the test. For constructed-response items, the item discrimination index used was the Pearson product-moment correlation; for multiplechoice items, the corresponding statistic is commonly referred to as a point-biserial correlation. The theoretical range of these statistics is -1.0 to 1.0 , with a typical observed range from 0.2 to 0.6 . All IRT statistics reported were within acceptable ranges according to the state's technical report.

External validity of the test was measured by comparing performance on the test to results from student questionnaires. Most of the questions asked about study habits with a subset designed to provide a measure of external validity. The relationship between the questionnaire data and performance was found to be consistent with evidence of external validity and meeting the Standards for Educational and Psychological Testing (AERA et al., 1999). In addition, steps were taken to ensure that different forms of the test across different years were equivalent using equating matrices.

\section{Data Processing Procedures and Data Analysis}

In linear regression, the regression coefficient is the constant that represents the rate of change of the response variable as a function of changes in the predictor variable, and is the slope of the regression line. Quantile regression estimates the rate of change in a specific quantile of the response variable produced by changes in the predictor variable. In this research quantile regression allows the comparison of percentiles in the distribution to estimate if achievement is significantly affected by 
gender at the high achievement tail. Additionally, covariates (e.g., race, LEP, and SES) may influence the distribution of mathematics achievement in numerous ways and quantile regression provides a more nuanced view of these relationships.

Quantile regression procedures were implemented with the statistical software package SAS utilizing the QUANTREG procedure. Where Ordinary Least Squares (OLS) regression is concerned with the central tendency $\mu$, quantile regression focuses on the $\tau$ th conditional quantile and its central tendency conventionally noted as $\xi$ (Gowlland, Xiao, \& Zeng, 2009). This research model represents the relationship among gender and other covariates (i.e., race, LEP, and SES), and the conditional quantiles of the response variable mathematics achievement $(Y)$. The results provide information about differences between achievement scores at selected points in the distribution. For example, results from the 0.89 decile compare the 0.89 decile of males' mathematics achievement distribution and the 0.89 decile of females' achievement scores. The formula is represented by $y_{i}=X_{i} \beta+\varepsilon_{i}$ where $y_{i}$ is the achievement score for student $i$ and $X_{i}$ includes the independent variables. As and Bassett (1978) demonstrate, this model can be estimated at the $\theta t h$ (theta) conditional quantile:

$$
\min _{\beta}\left[\sum_{\left\{i \mid y_{i} \geqslant X_{i} \beta\right\}} \theta\left|y_{i}-X_{i} \beta\right|+\sum_{\left\{i \mid y_{i}<X_{i} \beta\right\}}(1-\theta)\left|y_{i}-X_{i} \beta\right|\right]
$$

Note. Adapted from Penner and Paret (2008). Gender differences in mathematics achievement: Exploring the early grades and the extremes. Social Science Research, 37(1), p 343.

This estimates $\beta$ (beta) at different quantiles by changing the weights ( $\theta$ and $1-\theta$ ) 
of the positive and negative residuals. For example, at the median $(\theta=0.5)$ positive and negative residuals are given equal weight so that the sum of absolute deviations is minimized (Penner \& Paret, 2008).

The use of quantile regression in this study allows an examination of mathematics achievement data that would not be possible with traditional OLS regression methods. To provide a more complete understanding of how high levels of mathematics achievement are affected by gender, including interactions with covariates, requires a tool that illuminates specific segments of the distribution. Quantile regression is the methodological tool which allows this form of analysis. 


\section{CHAPTER 4}

\section{FINDINGS}

Before investigating the data with Quantile Regression, the population was examined at each grade level. SAS software was used to calculate all statistics and the PROC UNIVARIATE procedure revealed minor gendered differences in mean mathematics scores and standard deviations as shown in Table 9.

Table 9

Mathematics Scores Means and Standard Deviations by Gender and Grade

\begin{tabular}{lccc}
\hline Gender & $\begin{array}{c}\text { Grade } 4 \\
M(S D)\end{array}$ & $\begin{array}{c}\text { Grade 6 } \\
M(S D)\end{array}$ & $\begin{array}{c}\text { Grade 8 } \\
M(S D)\end{array}$ \\
\hline \multirow{2}{*}{ Males } & $443.00(13.26)$ & $642.40(13.26)$ & $840.06(11.59)$ \\
Females & $443.90(12.99)$ & $642.00(12.99)$ & $840.09(10.67)$ \\
\hline
\end{tabular}

One useful aspect of standard deviation is that it is expressed in the same units as the data, in this case the scaled mathematics scores. The standard deviations in Table 9 represent how much dispersion exists from the average mean score for each grade by gender. Results indicate that although mean scaled scores for males and females are extremely close, for all grades the variation of scores for males is greater than for females. In these data, the scores for males are spread out over a slightly larger range of values than the scores of females.

When beginning statistical analysis, it is good practice to visually inspect the entire distribution, and for this purpose histograms of the mathematics scores for each grade and gender were created. As seen in Figures 1, 2, and 3 slight departures from 
normality appear to exist in the population data and the distributions seem slightly skewed to the left.

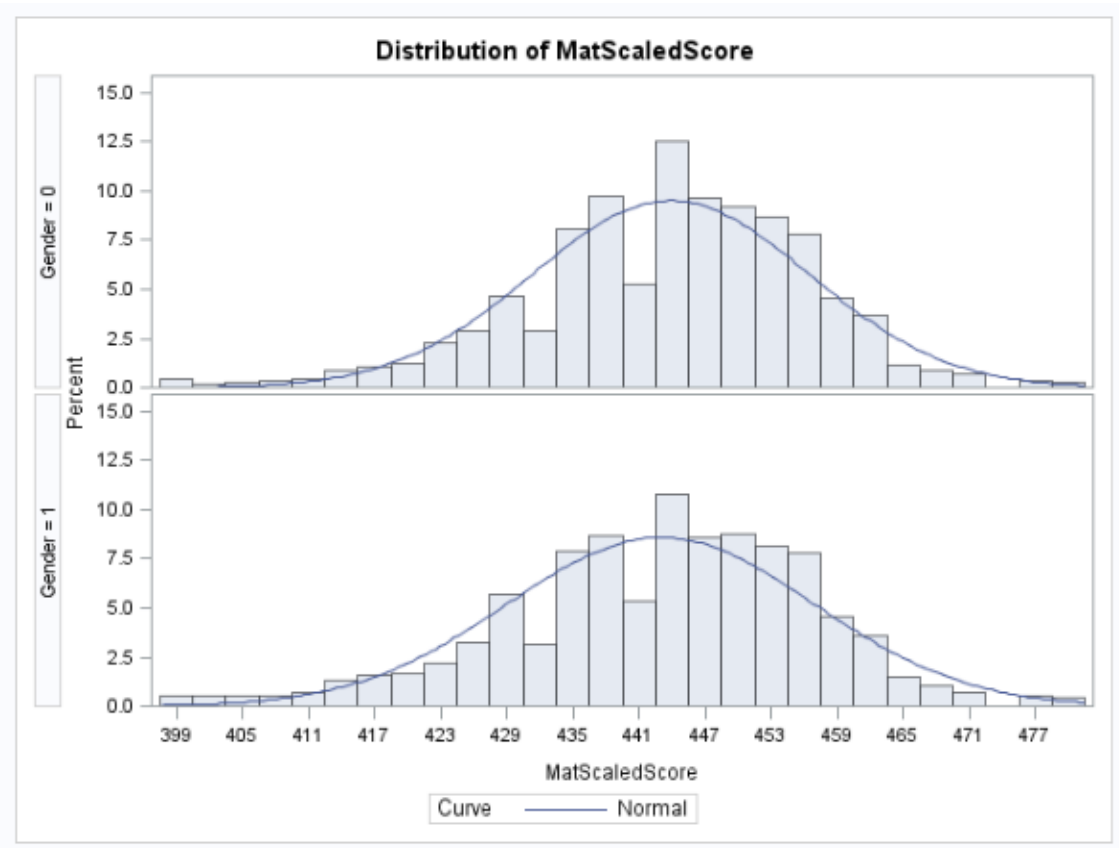

Figure 1. Scaled scores in mathematics for grade 4 students.

Female (Gender 0) and male (Gender 1) test takers with normal curve line.

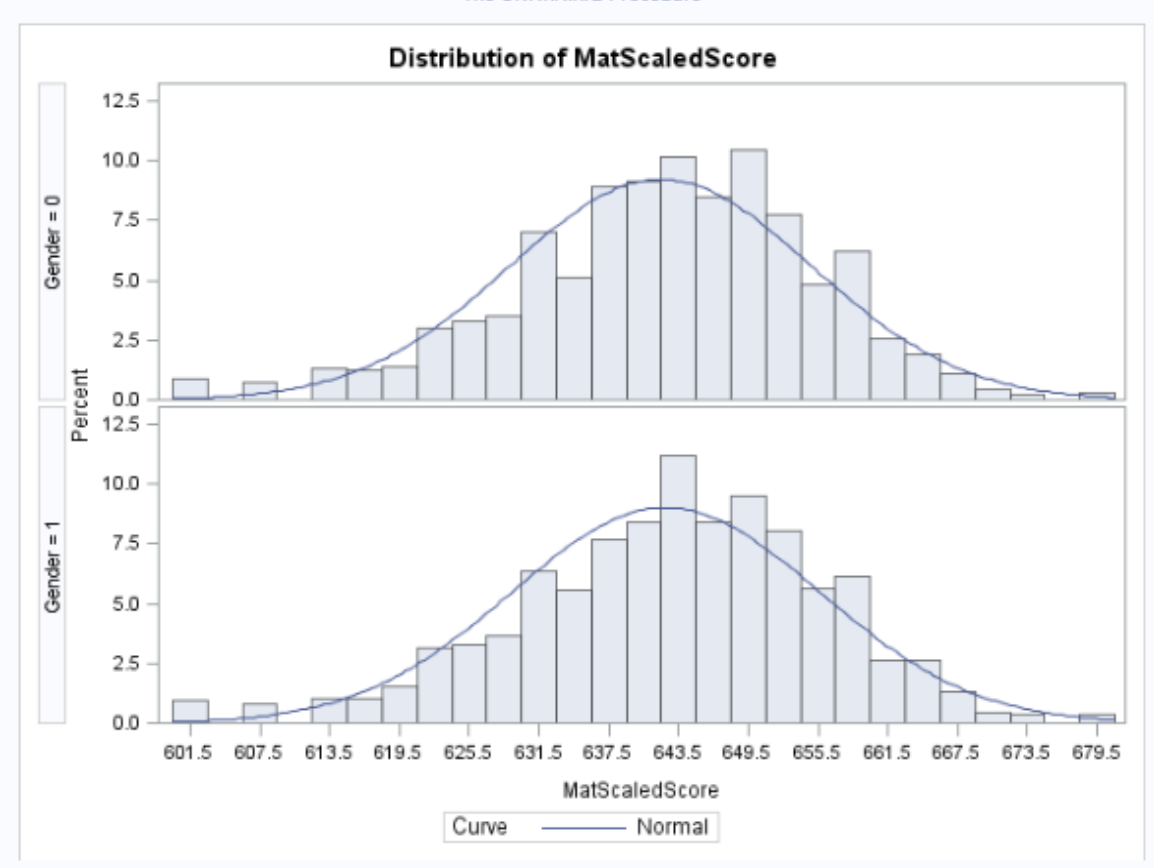

Figure 2. Scaled scores in mathematics for grade 6 students.

Female (Gender 0 ) and male (Gender 1) test takers with normal curve line. 


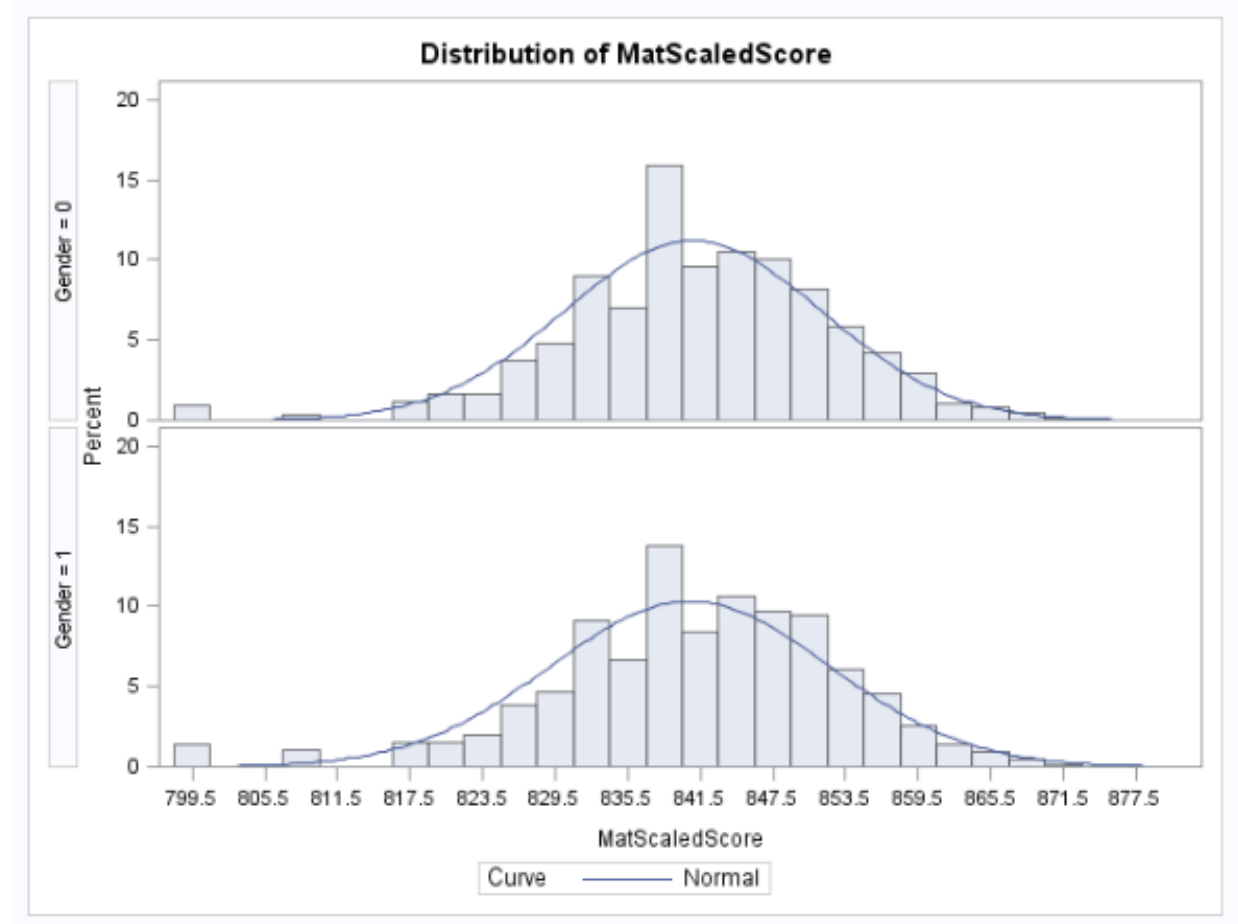

Figure 3. Scaled scores in mathematics for grade 8 students.

Female (Gender 0 ) and male (Gender 1) test takers with normal curve line.

Further analysis of skewness in the distributions was conducted and the results are shown in Table 10. Negative direction of skew is confirmed, but grades 4, 6, and grade 8 females all fall within the 0.50 to -0.50 which are the skewness boundaries for this size $n$ (Montgomery, Peck, \& Vining, 2006). Grade 8 males at -0.66 only slightly exceed this range and so the distribution for eighth grade boys is considered to be moderately skewed to the left (Montgomery, Peck, \& Vining, 2006).

Table 10

Analysis of Distribution Skew

\begin{tabular}{ccr}
\hline Grade & Gender & Skewness \\
\hline 4 & females & -0.464 \\
4 & males & -0.468 \\
6 & females & -0.413 \\
6 & males & -0.404 \\
8 & females & -0.462 \\
8 & males & -0.663 \\
\hline
\end{tabular}


Quantile-quantile (Q-Q) plots are useful for comparing a specified normal distribution with the estimation of values of a variable and Q-Q plots were created to explore the distributions, shown in Figures 4, 5, and 6. The Q-Q plots of all grades' mathematics scores by gender are fairly linear with some departure at both tails of the distributions in all cases.

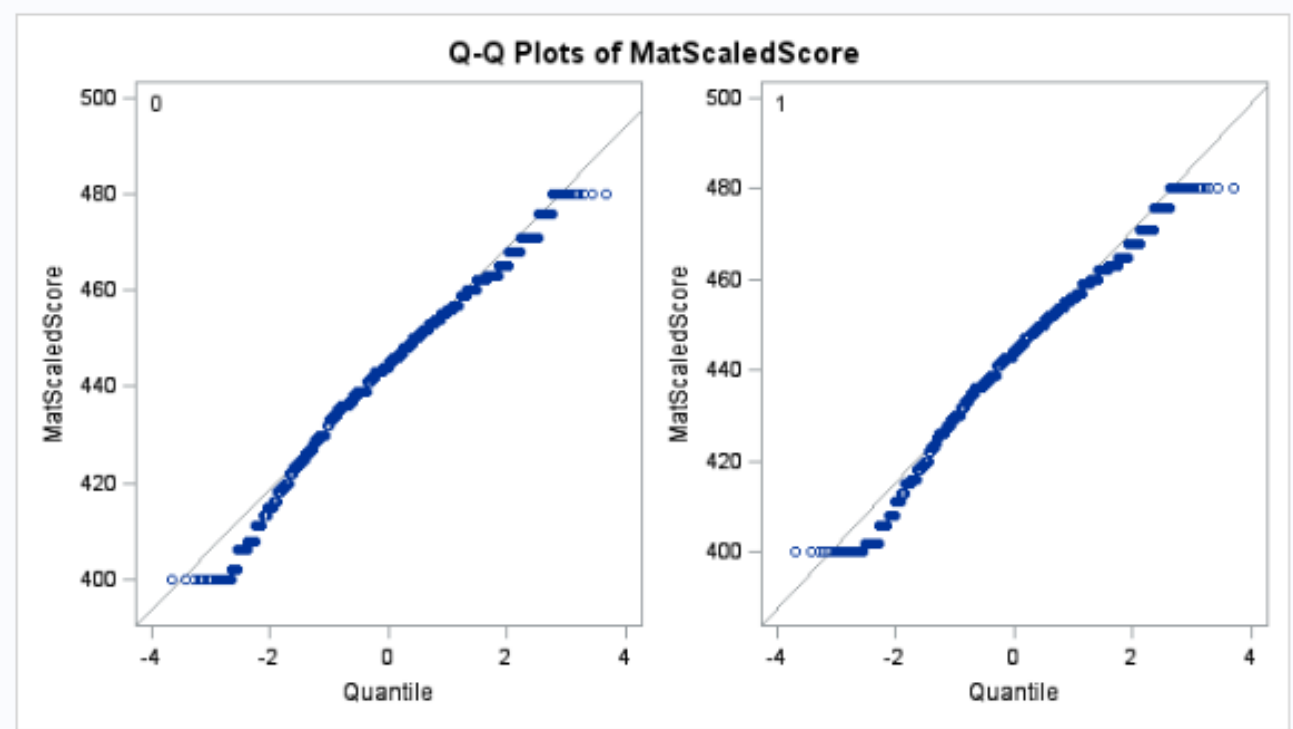

Figure 4. Grade 4 scaled scores in mathematics by female and male test takers with regression line. Plot on the right represents female scores, plot on the left represents male scores.

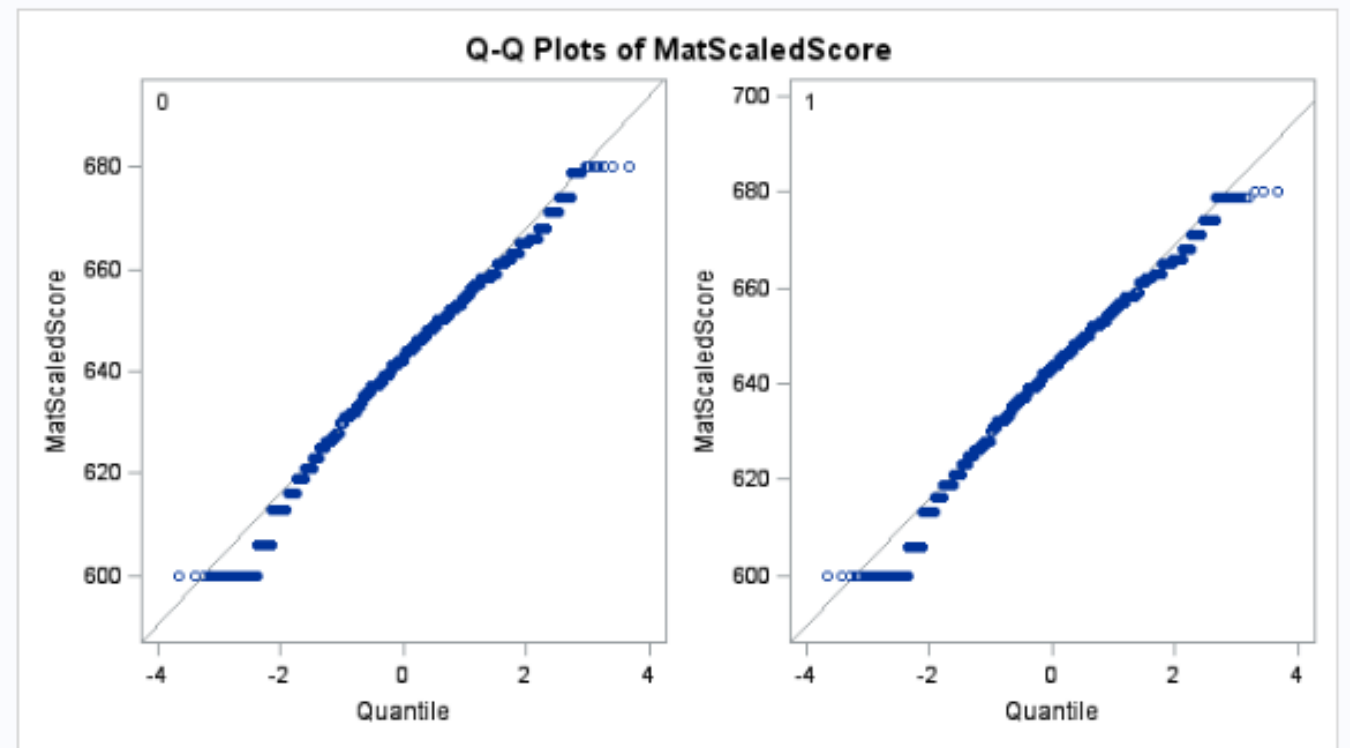

Figure 5. Grade 6 scaled scores in mathematics by female and male test takers with regression line. 


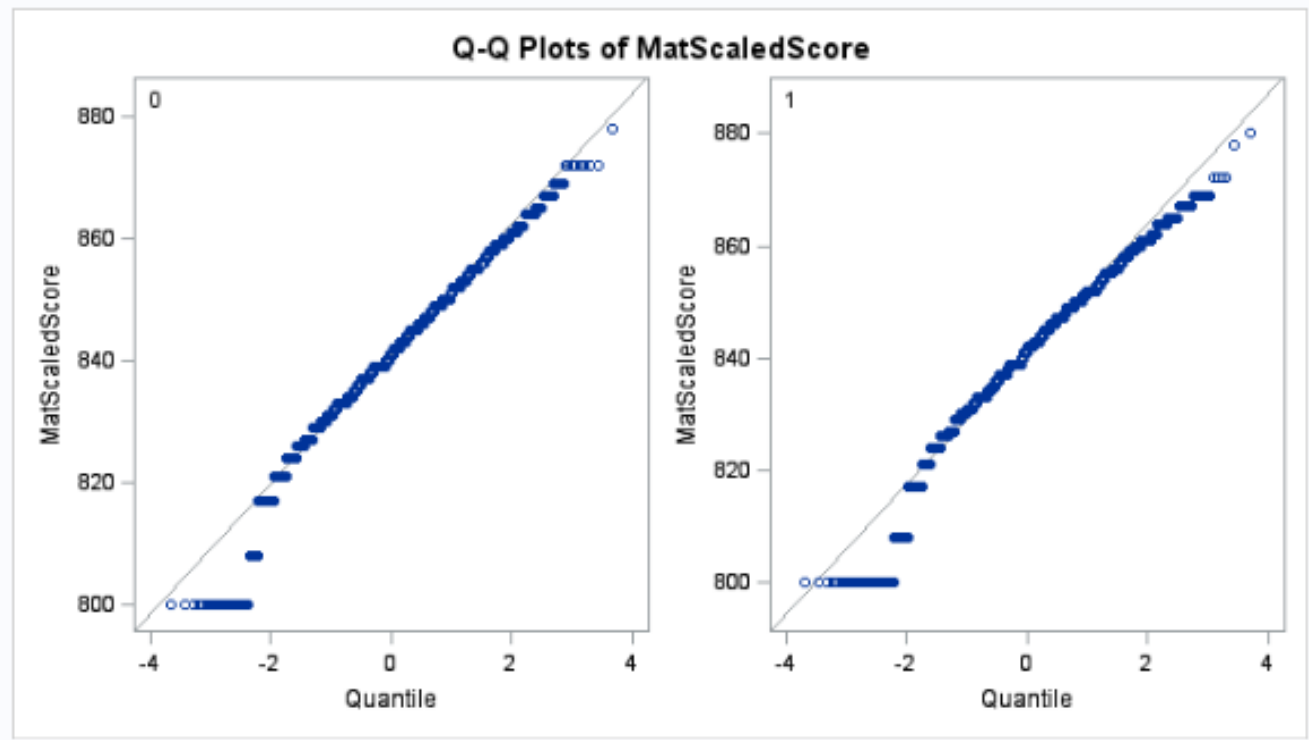

Figure 6. Grade 8 scaled scores in mathematics by female (Gender 0) and male (Gender 1) test takers with regression line.

\section{Quantile Regression}

Use of quantile regression allows exploration of specific regions of a distribution and more accurately represents the outlying areas than methods such as Ordinary Least Squares (OLS), especially for distributions which may not be normal or which show departure in the tails (Hao \& Naiman, 2007), as in Figures 4, 5, and 6. Quantile regression estimates the conditional quantiles of a response variable expressed as a function of covariates in specified segments of a distribution (deciles, percentiles, quintiles, or fractiles) (Koenker and Hallock, 2001). This makes precise analysis possible, even with a non-normal distribution. This is appropriate methodology when considering distributions with unequal variation (Hao \& Naiman, 2007) or when locus of interest is at the extreme levels of the data as in this investigation. In these data where the tails are departing somewhat from normality, as evidenced by the Q-Q plots, quantile regression is a suitable methodological choice. 
Using SAS software and the PROC QUANTREG procedure to examine the data with quantile regression, the population of mathematics scores was divided into deciles with intervals of 0.10 in each group, creating 10 groups beginning with the $0.09^{\text {th }}$ decile and ending at the $0.99^{\text {th }}$ decile. Separate means of mathematics scores were calculated for each quantile and analyses of the predictive effects of gender were conducted. The consequences of gender described as negative, positive, or no changes in mathematics score points were revealed at all quantiles of achievement through these analyses and reported when the $p$ value was equal to or less than .05 , a traditional measure of significance. The effects of gender on mathematics scores for each decile are displayed in Table 11.

With males chosen as the reference group, grade 4 results revealed a two-point advantage for females in their mathematics scores at the lowest quantiles of achievement. Conversely, this can be thought of as a male disadvantage of two-points in the group of students with the lowest scores, had females been used as the reference. Towards the center of the distribution this advantage disappears but reemerges as a one-point advantage for females at the 0.69 and 0.89 deciles. For grade 4 students, girls' mathematics achievement in these data exceed or equal boys'.

In grade 6 data, the evidence of a female advantage in the lower test score deciles that was seen in grade 4 no longer appears. In the center of the distribution girls are disadvantaged by one-point and equal again at the 0.59 decile. In the 0.69 , 0.79 , and 0.89 deciles girls are consistently performing one-point lower than their male peers on this mathematics test. In the highest achieving student group at the 0.99 decile female scores fall to a three-point disadvantage when compared to their male 
peers. It is helpful to recall in this analysis that these results can also be interpreted as a three-point advantage to males in the 0.99 decile.

The scores of students in eighth grade show a pattern of females having an advantage of one-point at the bottom of score ranges and a disadvantage of one-point at the top, beginning at the 0.59 decile and extending through the 0.99 th. The center of the range reveals no gender difference for this population.

Table 11

Consequence of Gender on Mathematics Score in Each Quantile by Grade

\begin{tabular}{|c|c|c|c|c|c|c|c|c|c|c|}
\hline Grade 4 & & & & & & & & & & \\
\hline Quantiles & 0.09 & 0.19 & 0.29 & 0.39 & 0.49 & 0.59 & 69 & 0.79 & 0.89 & 0.99 \\
\hline Male & 0 & 0 & 0 & 0 & 0 & 0 & 0 & 0 & 0 & 0 \\
\hline Female & 2 & 2 & 2 & 1 & 0 & 0 & 1 & 0 & 1 & 0 \\
\hline Predicted Value & 424 & 432 & 436 & 441 & 444 & 447 & 450 & 454 & 459 & 471 \\
\hline \multicolumn{11}{|l|}{ Grade 6} \\
\hline Quantiles & 0.09 & 0.19 & 0.29 & 0.39 & 0.49 & 0.59 & 0.69 & 0.79 & 0.89 & 0.99 \\
\hline Male & 0 & 0 & 0 & 0 & 0 & 0 & 0 & 0 & 0 & 0 \\
\hline Female & 0 & 0 & 0 & 0 & $\begin{array}{l}-1 \\
\end{array}$ & 0 & -1 & -1 & $\begin{array}{l}-1 \\
\end{array}$ & -3 \\
\hline Predicted Value & 625 & 632 & 636 & 639 & 643 & 646 & 650 & 653 & 658 & 671 \\
\hline \multicolumn{11}{|l|}{ Grade 8} \\
\hline Quantiles & 0.09 & 0.19 & 0.29 & 0.39 & 0.49 & 0.59 & 69 & 0.79 & 0.89 & 0.99 \\
\hline Male & 0 & 0 & 0 & 0 & 0 & 0 & 0 & 0 & 0 & 0 \\
\hline Female & 1 & 1 & 1 & 0 & 0 & -1 & -1 & -1 & -1 & -1 \\
\hline Predicted Value & 826 & 832 & 835 & 839 & 841 & 844 & 847 & 850 & 854 & 865 \\
\hline
\end{tabular}

The State's rating system segments individual students' mathematics scaled scores into four achievement levels; Proficient with Distinction, Proficient, Partially Proficient, and Substantially Below Proficient, each level separated by just one scaled 
point. All scores are reported on 80-point scales corresponding to each grade level (400-480 for grade 4, 600-680 for grade 6 , and 800-880 for grade 8 ). The scales have been developed so that a score of 40 represents Proficient performance at every grade level. Table 12 shows the scaled scores that identify the cut point between mathematics achievement levels and the change in designation due to a one-point score difference.

Table 12

Achievement Level Cut Scores in Mathematics

\begin{tabular}{cccc}
\hline & $\begin{array}{l}\text { Substantially Below } \\
\text { Proficient/ } \\
\text { Partially Proficient }\end{array}$ & $\begin{array}{l}\text { Partially Proficient/ } \\
\text { Proficient }\end{array}$ & $\begin{array}{l}\text { Proficient/ } \\
\text { Proficient with Distinction }\end{array}$ \\
\hline Grade 4 & $430 / 431$ & $439 / 440$ & $454 / 455$ \\
Grade 6 & $632 / 633$ & $639 / 640$ & $652 / 653$ \\
Grade 8 & $833 / 834$ & & $851 / 852$ \\
\hline
\end{tabular}

It is clear from the initial analysis that a simple reporting of central tendencies for this data, as shown in Table 9, would suggest that males and females have equal achievement on the mathematics tests, when the reality is more complex. The state from which the data originates reports that the number of scaled score points denoting statistical significance for a group of 200 or more students is one-point (Rhode Island Department of Education, 2011). By this measure then, the point advantages and disadvantages revealed by quantile regression are impactful to both males and females, while relying on overall mean difference in scores leads to an incomplete conclusion regarding equity and mathematics. 


\section{Interactions of Mathematics Scores, Gender, and SES}

Students' socioeconomic status (SES) has been positively linked to achievement in educational research in numerous studies (McGraw, Lubienski, \& Strutchens, 2006; Sirin, 2005; Ladd, 2012). In the present investigation, SES contributes significantly to the model as revealed at each decile through the QUANTREG procedure. SES in this study is described by participation (SES 1) or non-participation (SES 0) in the federally supported free or reduced lunch program offered through all school systems in the state. Analysis was conducted with mathematics scaled scores as the dependent variable and gender as a covariate with the addition of the variable SES.

Results for grade 4 are shown in Table 13. In the lowest scoring levels of mathematics achievement, there is a clear advantage for students who do not participate in a free or reduced lunch who have a 10- to 12-point advantage over their peers participating in free or reduced lunch programs. This finding can also be thought of as a 10- to 12-point disadvantage to students with lower SES. The advantage of higher economic status is revealed throughout the range of scores and is never less than an eight-point difference between the two groups.

At this grade level, SES does not appear to differentially affect males and females and no interactions of significance are revealed. Interestingly, the consequence of being female is moderated through the addition of SES to the model and females appear to have a greater advantage in the lowest scoring range when the covariate SES is included. Since females had a two-point advantage at the lowest scoring decile when socioeconomic status was not considered and the addition of SES 
to the model increases this to a four-point advantage, it can be interpreted that higher socioeconomic status is a greater advantage to low scoring females in the grade 4 population.

Table 13

Grade 4 Mathematics Score, Gender, and SES

\begin{tabular}{lrrrrrrrrrr}
\hline Quantiles & 0.09 & 0.19 & 0.29 & 0.39 & 0.49 & 0.59 & 0.69 & 0.79 & 0.89 & 0.99 \\
\hline Male & 0 & 0 & 0 & 0 & 0 & 0 & 0 & 0 & 0 & 0 \\
Female & 4 & 2 & 2 & 1 & 0 & 0 & 0 & 0 & 0 & 0 \\
SES 0 & 12 & 10 & 10 & 9 & 9 & 9 & 9 & 8 & 8 & 11 \\
SES 1 & 0 & 0 & 0 & 0 & 0 & 0 & 0 & 0 & 0 & 0 \\
Male*SES 0 & 0 & 0 & 0 & 0 & 0 & 0 & 0 & 0 & 0 & 0 \\
Male*SES 1 & 0 & 0 & 0 & 0 & 0 & 0 & 0 & 0 & 0 & 0 \\
Female*SES 0 & 0 & 0 & 0 & 0 & 0 & 0 & 0 & 0 & 0 & 0 \\
Female*SES 1 & 0 & 0 & 0 & 0 & 0 & 0 & 0 & 0 & 0 & 0 \\
Predicted Value & 418 & 427 & 432 & 436 & 439 & 443 & 445 & 449 & 454 & 465 \\
\hline
\end{tabular}

Note: Socioeconomic status (SES) as described by free/reduced lunch status where SES 0 is no participation in free/reduced lunch program and SES 1 indicates eligibility for free/reduced lunch program.

When SES is added to the quantile regression model with sixth grade test score data, the advantage for students who do not participate in the free or reduced lunch programs (coded SES 0) is significant at all deciles. As seen in Table 14 students labeled SES 0 gain from 10- to 12-point across the distribution, an effect even greater than effects seen at grade 4. An interaction between being female and having free/reduced lunch status is revealed at the .99th deciles as a four-point disadvantage. This can also be interpreted as revealing a four-point advantage to males of higher economic status. In addition, at the 0.69 decile all females have a disadvantage of onepoint. 
Table 14

Grade 6 Mathematics Score, Gender, and SES

\begin{tabular}{lrrrrrrrrrr}
\hline Quantiles & 0.09 & 0.19 & 0.29 & 0.39 & 0.49 & 0.59 & 0.69 & 0.79 & 0.89 & 0.99 \\
\hline Male & 0 & 0 & 0 & 0 & 0 & 0 & 0 & 0 & 0 & 0 \\
Female & 0 & 0 & 0 & 0 & 0 & 0 & -1 & 0 & 0 & 0 \\
SES 0 & 12 & 11 & 10 & 10 & 11 & 10 & 10 & 11 & 10 & 12 \\
SES 1 & 0 & 0 & 0 & 0 & 0 & 0 & 0 & 0 & 0 & 0 \\
Male*SES 0 & 0 & 0 & 0 & 0 & 0 & 0 & 0 & 0 & 0 & 0 \\
Male*SES 1 & 0 & 0 & 0 & 0 & 0 & 0 & 0 & 0 & 0 & 0 \\
Female*SES0 & 0 & 0 & 0 & 0 & -1 & 0 & 0 & 0 & 0 & -4 \\
Female*SES1 & 0 & 0 & 0 & 0 & 0 & 0 & 0 & 0 & 0 & 0 \\
Predicted Value & 619 & 626 & 631 & 634 & 637 & 640 & 643 & 646 & 651 & 662 \\
\hline
\end{tabular}

Note: Socioeconomic status (SES) as described by free/reduced lunch status where SES 0 is no participation in free/reduced lunch program and SES 1 indicates eligibility for free/reduced lunch program.

Building the quantile regression model using mathematics scaled score, gender, and SES with data from the eighth grade population demonstrates again the significant role of socioeconomic status on achievement in this group. Once again there is a pattern of advantage across the distribution for students who do not participate in free or reduced lunch programs. In the case of the eighth grade data shown in Table 15, this benefit ranges from six to eight-point gains across the range of scores. The female advantage of one-point in the lower range at the 0.19 decile found without SES as a covariate increases to two-points when higher socioeconomic status interacts with being female. The disadvantage of negative one-point to females at the upper decile of 0.89 that was evident without the inclusion of variable SES is moderated to a two-point advantage to females of higher SES. The impact of higher economic status in these examples can be interpreted as having a positive effect on mathematics achievement for females in this population. 
Table 15

Grade 8 Mathematics Score, Gender, and SES

\begin{tabular}{lrrrrrrrrrr}
\hline Quantiles & 0.09 & 0.19 & 0.29 & 0.39 & 0.49 & 0.59 & 0.69 & 0.79 & 0.89 & 0.99 \\
\hline Male & 0 & 0 & 0 & 0 & 0 & 0 & 0 & 0 & 0 & 0 \\
Female & 0 & 0 & 0 & 0 & 0 & 0 & -1 & -1 & -2 & 0 \\
SES 0 & 6 & 6 & 7 & 8 & 8 & 8 & 8 & 7 & 7 & 7 \\
SES 1 & 0 & 0 & 0 & 0 & 0 & 0 & 0 & 0 & 0 & 0 \\
Male*SES 0 & 0 & 0 & 0 & 0 & 0 & 0 & 0 & 0 & 0 & 0 \\
Male*SES 1 & 0 & 0 & 0 & 0 & 0 & 0 & 0 & 0 & 0 & 0 \\
Female*SES0 & 0 & 2 & 0 & 0 & 0 & 0 & 0 & 0 & 2 & 0 \\
Female*SES1 & 0 & 0 & 0 & 0 & 0 & 0 & 0 & 0 & 0 & 0 \\
Predicted Value & 824 & 829 & 832 & 834 & 837 & 839 & 842 & 845 & 849 & 858 \\
\hline
\end{tabular}

Note: Socioeconomic status (SES) as described by free/reduced lunch status where SES 0 is no participation in free/reduced lunch program and SES 1 indicates eligibility for free/reduced lunch program.

\section{Interaction of Mathematics Scaled Score, Gender, and LEP}

To investigate the relationships between mathematics scaled score, gender, and students with limited proficiency in English (LEP) the QUANTREG model was used and results were analyzed. Participation in these classes is categorized by the state reporting agency as LEP 0 (no participation), LEP 1 (first year participation), LEP 2 (second year, monitored), or LEP 3 (third year, monitored). In all grades analyzed, second and third year status of being monitored (LEP 2, LEP 3) showed no statistically significant effect or interaction and so are not included in Tables 16, 17, or 18. As shown in Table 4, students categorized as having limited proficiency in English represent a very small proportion of the population in this study ranging from $3.2 \%$ to $6.4 \%$. When the quantile regression model was applied using 10 deciles, as with other covariates, results for LEP status were meaningless due to the small percentage of students represented at many deciles. Therefore, in the analyses of student 
achievement, gender, and the variable limited proficiency in English, the data were grouped into sections at the $0.25,0.50$, and 0.75 quantiles.

The grade 4 results in Table 16 demonstrate the consequences of having limited proficiency with English for students. The effects on mathematics scores range from -5 to -11.29 -points for both genders. At the 0.25 quartile students who are not categorized as limited in English proficiency gain an additional nine-points over peers with LEP status. No interactions occur with gender in this grade leading to a conclusion that status or non-status as an English language learner affects both genders similarly in this fourth grade population.

Table 16

Grade 4 Mathematics Score, Gender, and LEP

\begin{tabular}{lrrr}
\hline Quantiles & 0.25 & 0.5 & 0.75 \\
\hline Male & 0.00 & 0.00 & 0.00 \\
Female & 0.00 & 0.00 & 0.00 \\
LEP 0 & 9.00 & 0.00 & 0.00 \\
LEP 1 & -5.00 & -11.29 & -11.00 \\
Male*LEP 0 & 0.00 & 0.00 & 0.00 \\
Male*LEP 1 & 0.00 & 0.00 & 0.00 \\
Female*LEP 0 & 0.00 & 0.00 & 0.00 \\
Female*LEP 1 & 0.00 & 0.00 & 0.00 \\
Predicted Value & 427.00 & 443.29 & 450.00 \\
\hline
\end{tabular}

Note: Limited English Proficiency (LEP) as described by participation in language support programs for English language learners where LEP 0 is no participation and LEP 1 indicates student is in year one of participation in English language support classes, LEP 2 indicates first year monitored status.

The analysis of sixth grade mathematics scores by covariates gender and LEP reveal an increasingly negative consequence to students who are English language learners as they move to higher grade levels. Beginning at the lowest range of scores 
these students are 14- to 15-points lower scoring than their more English proficient peers as shown in Table 17. Similar to results for fourth grade data, there is no interaction with gender in the sixth grade population.

Table 17

Grade 6 Mathematics Score, Gender, and LEP

\begin{tabular}{lrrr}
\hline Quantiles & 0.25 & 0.5 & 0.75 \\
\hline Male & 0.00 & 0.00 & 0.00 \\
Female & 0.00 & 0.00 & 0.00 \\
LEP 0 & 0.00 & 0.00 & 0.00 \\
LEP 1 & -15.00 & -15.00 & -14.00 \\
Male*LEP 0 & 0.00 & 0.00 & 0.00 \\
Male*LEP 1 & 0.00 & 0.00 & 0.00 \\
Female*LEP 0 & 0.00 & 0.00 & 0.00 \\
Female*LEP 1 & 0.00 & 0.00 & 0.00 \\
Predicted Value & 634.00 & 642.00 & 647.00 \\
\hline
\end{tabular}

Note: Limited English Proficiency (LEP) as described by participation in language support programs for English language learners where LEP 0 is no participation and LEP 1 indicates student is in year one of participation in English language support classes.

The data from grade 8 student scores reveal an advantage for students not categorized with limited proficiency in English of 7.02-points at the 0.75 quantile, shown in Table 18. The negative effect of LEP 1 status seen in grades 4 and 6 are not found at significant levels for the grade 8 population. In addition, the data does not suggest interaction between LEP status and gender in grade 8 . 
Table 18

Grade 8 Mathematics Score, Gender, and LEP

\begin{tabular}{lccc}
\hline Quantiles & 0.25 & 0.5 & 0.75 \\
\hline Male & 0.00 & 0.00 & 0.00 \\
Female & 0.00 & 0.00 & 0.00 \\
LEP 0 & 0.00 & 0.00 & 7.02 \\
LEP 1 & 0.00 & 0.00 & 0.00 \\
Male*LEP 0 & 0.00 & 0.00 & 0.00 \\
Male*LEP 1 & 0.00 & 0.00 & 0.00 \\
Female*LEP 0 & 0.00 & 0.00 & 0.00 \\
Female*LEP 1 & 0.00 & 0.00 & 0.00 \\
Predicted Value & 829.00 & 837.23 & 841.97 \\
\hline
\end{tabular}

Note: Limited English Proficiency (LEP) as described by classes. participation in language support programs for English language learners where LEP 0 is no participation and LEP 1 indicates student is in year one of participation in English language support

Interactions of Mathematics Scores, Gender, and Race

At each grade level the quantile regression model was used to analyze the dependent variable mathematics scaled score with covariates gender and race. The data provided by the testing state partition race into seven categories that were maintained for this study. These categories are American Indian/Alaskan Native, Asian, Black/African American, Hispanic/Latino, Native Hawaiian/Pacific Islander, White, or Two or More Races. Students who were not coded for race have no results that could be interpreted through this analysis and were omitted in this aspect of the model. From the population these omitted scores comprise less than $1 \%$ of the population (56 students from grade 4, 45 from grade 5, and 71 from grade 8).

These data demonstrate that achievement is impacted uniquely by different races at various deciles in these data. Throughout investigations for all three grades using race as a covariate, racial groups of smaller student representation evidenced 
significant findings. Although difficult to interpret due to the small $n$, exclusion of these groups would potentially marginalize those with minority status as well as ignore findings that may indicate areas for future research. Therefore all identified racial groups are included in this analysis.

At the fourth grade, there is a negative consequence to students coded American Indian/Alaskan Native which is most significant at the lowest levels of achievement. Being designated as Black/African American or Hispanic/Latino, negatively impacts scores in this group throughout the entire range, as seen in Table 19. The consequence of race status code White is positive or neutral in this model and, along with status as Asian, adds the most benefit to those scores in the highest scoring 0.99 decile.

A closer examination of the population of American Indian/Alaskan Native students reveals it includes only 71 students. The students represented in this ethnic group at significantly impacted deciles are small in number (19 students at $0.09,11$ students at $0.19,10$ students at 0.29 , and five students at 0.39 ). These small subgroups make interpretation difficult but may point to an area for future research.

When compared with American Indian/Alaskan Natives, Black and Hispanic students in fourth grade represent a much greater number, with 336 and 845 students in these groups respectively. Results using quantile regression can therefore be interpreted as revealing negative consequences at all levels of mathematics achievement for fourth grade students who are either Black or Hispanic in this population. 
Table 19

Grade 4 Mathematics Score, Gender, and Race

\begin{tabular}{|c|c|c|c|c|c|c|c|c|c|c|}
\hline Quantiles & 0.09 & 0.19 & 0.29 & 0.39 & 0.49 & 0.59 & 0.69 & 0.79 & 0.89 & 0.99 \\
\hline Male & 0 & 0 & 0 & 0 & 0 & 0 & 0 & 0 & 0 & 0 \\
\hline Female & 8 & 0 & 0 & 5 & 0 & 0 & 0 & 0 & 0 & 0 \\
\hline $\begin{array}{l}\text { American Indian/ } \\
\text { Alaskan Native }\end{array}$ & -9 & -11 & -10 & -9 & 0 & -8 & -5 & 0 & 0 & 0 \\
\hline Asian & 0 & 0 & 0 & 0 & 5 & 5 & 4 & 0 & 0 & 12 \\
\hline $\begin{array}{l}\text { Black/African } \\
\text { Amer. }\end{array}$ & -9 & -6 & -6 & -5 & -5 & -7 & -7 & -7 & -8 & -3 \\
\hline Hispanic/Latino & -7 & -4 & -6 & -5 & -4 & -4 & -6 & -6 & -8 & -5 \\
\hline White & 4 & 6 & 0 & 4 & 5 & 4 & 3 & 4 & 0 & 8 \\
\hline $\begin{array}{l}\text { Two or More } \\
\text { Races }\end{array}$ & 0 & 0 & 0 & 0 & 0 & 0 & 0 & 0 & 0 & 0 \\
\hline $\begin{array}{l}\text { Male*Amer.Ind.I } \\
\text { Alaskan Native }\end{array}$ & 0 & 0 & 0 & 0 & 0 & 0 & 0 & 0 & 0 & 0 \\
\hline $\begin{array}{l}\text { Female*Amer. Ind.I } \\
\text { Alaskan Native }\end{array}$ & 0 & 0 & 0 & 0 & 0 & 0 & 0 & 0 & 0 & -12 \\
\hline Male*Asian & 0 & 0 & 0 & 0 & 0 & 0 & 0 & 0 & 0 & 0 \\
\hline Female*Asian & 0 & 0 & 0 & 0 & 0 & 0 & 0 & 0 & 0 & -7 \\
\hline Male*Black & 0 & 0 & 0 & 0 & 0 & 0 & 5 & 0 & 0 & 0 \\
\hline Female*Black & 0 & 0 & 0 & 0 & 0 & 4 & 4 & 0 & 0 & -6 \\
\hline Male*Hispanic & 0 & 0 & 0 & 0 & 0 & 0 & 0 & 0 & 0 & 0 \\
\hline Female*Hispanic & 0 & 0 & 0 & 0 & 0 & 0 & 0 & 0 & 0 & -4 \\
\hline Male*White & 0 & 0 & 0 & 0 & 0 & 0 & 0 & 0 & 0 & 0 \\
\hline Female*White & 0 & 0 & 0 & 0 & 0 & 0 & 0 & 0 & 0 & -8 \\
\hline Predicted Value & 425 & 430 & 436 & 439 & 442 & 446 & 450 & 454 & 460 & 468 \\
\hline
\end{tabular}

The grade 6 data were examined with covariates gender and race and dependent variable mathematics scaled score. Similar patterns for racial status as Black/African American or Hispanic/Latino as those found in grade 4 are revealed, and all deciles show a negative impact on scores for these two groups as displayed in Table 20. At the 0.99 decile for grade 6, the consequence of being Black/African American is a loss of 16-points and for being Hispanic/Latino a loss of 17-points. Sixth grade students in this group who are labeled White, once again are positively impacted in nearly all deciles, but reveal a -8-points at the 0.99 percentile. 
Table 20

Grade 6 Mathematics Score, Gender, and Race

\begin{tabular}{|c|c|c|c|c|c|c|c|c|c|c|}
\hline Quantiles & 0.09 & 0.19 & 0.29 & 0.39 & 0.49 & 0.59 & 0.69 & 0.79 & 0.89 & 0.99 \\
\hline Male & 0 & 0 & 0 & 0 & 0 & 0 & 0 & 0 & 0 & 0 \\
\hline Female & 0 & 0 & 0 & 0 & 0 & 0 & 0 & 0 & 0 & -11 \\
\hline $\begin{array}{l}\text { American Ind.I } \\
\text { Alaskan Native }\end{array}$ & 0 & 0 & 0 & -6 & -8 & -5 & -5 & -7 & -9 & ${ }^{* * * \star}(0)$ \\
\hline Asian & 0 & 0 & 0 & 4 & 3 & 4 & 5 & 5 & 6 & 0 \\
\hline $\begin{array}{l}\text { Black/African } \\
\text { Amer. }\end{array}$ & -6 & -5 & -7 & -6 & -7 & -6 & -5 & -7 & -6 & -16 \\
\hline Hispanic/Latino & -6 & -6 & -5 & -5 & -5 & -6 & -5 & -5 & -5 & -17 \\
\hline White & 0 & 5 & 4 & 5 & 4 & 4 & 5 & 4 & 4 & -8 \\
\hline $\begin{array}{l}\text { Two or More } \\
\text { Races }\end{array}$ & 0 & 0 & 0 & 0 & 0 & 0 & 0 & 0 & 0 & 0 \\
\hline $\begin{array}{l}\text { Male*Amer. Ind.I } \\
\text { Alas. Native }\end{array}$ & 0 & 0 & 0 & 0 & 0 & 0 & 0 & 0 & 0 & 0 \\
\hline $\begin{array}{l}\text { Female*Amer. } \\
\text { Ind.I } \\
\text { Alas. Native }\end{array}$ & 0 & 0 & 0 & 0 & 0 & 0 & 0 & 0 & 0 & 16 \\
\hline Male*Asian & 0 & 0 & 0 & 0 & 0 & 0 & 0 & 0 & 0 & 0 \\
\hline Female*Asian & 0 & 0 & 0 & 0 & 0 & 0 & 0 & 0 & 0 & -7 \\
\hline Male`Black & 0 & 0 & 0 & 0 & 0 & 0 & 0 & 0 & 0 & 0 \\
\hline Female*Black & 0 & 0 & 0 & 0 & 0 & 0 & 0 & 0 & 0 & ${ }^{* * * *}(4)$ \\
\hline Male*Hispanic & 0 & 0 & 0 & 0 & 0 & 0 & 0 & 0 & 0 & 0 \\
\hline Female*Hispanic & 0 & 0 & 0 & 0 & 0 & 0 & 0 & 0 & 0 & 0 \\
\hline Male*White & 0 & 0 & 0 & 0 & 0 & 0 & 0 & 0 & 0 & 0 \\
\hline Female*White & 0 & 0 & 0 & 0 & 0 & 0 & 0 & 0 & 0 & 11 \\
\hline Predicted Value & 625 & 631 & 635 & 638 & 642 & 645 & 647 & 651 & 655 & 679 \\
\hline
\end{tabular}

Note: Groups less than 5 represented by ${ }^{* * *}$ followed by exact $(n)$.

A quantile regression model was developed for eighth grade scores with mathematics scaled scores, gender, and race used as variables once again. In these results, patterns for status as Black/African American or Hispanic/Latino remained similar to those found at grades 4 and 6 with the notable exception of the 0.99 decile where there is no consequence of race for either group as seen in Table 21. 
Table 21

Grade 8 Mathematics Score, Gender, and Race

\begin{tabular}{|c|c|c|c|c|c|c|c|c|c|c|}
\hline Quantiles & 0.9 & 0.19 & 0.29 & 0.39 & 0.49 & 0.59 & 0.69 & 0.79 & 0.89 & 0.99 \\
\hline Male & 0 & 0 & 0 & 0 & 0 & 0 & 0 & 0 & 0 & 0 \\
\hline Female & 0 & 0 & 0 & 0 & 0 & -3 & -4 & 0 & -6 & 0 \\
\hline $\begin{array}{l}\text { American Indian/ } \\
\text { Alaskan Native }\end{array}$ & 0 & 0 & -7 & -8 & -7 & -9 & -8 & -7 & -9 & 0 \\
\hline Asian & 0 & 0 & 0 & 0 & 0 & 3 & 0 & 4 & 0 & 0 \\
\hline $\begin{array}{l}\text { Black/African } \\
\text { American }\end{array}$ & -6 & -7 & -7 & -6 & -6 & -6 & -7 & -6 & -8 & ${ }^{* * * *}(0)$ \\
\hline Hispanic/Latino & -6 & -6 & -6 & -6 & -6 & -6 & -7 & -6 & -8 & 0 \\
\hline White & 0 & 0 & 0 & 0 & 0 & 0 & 0 & 0 & 0 & 0 \\
\hline $\begin{array}{l}\text { Two or More } \\
\text { Races }\end{array}$ & 0 & 0 & 0 & 0 & 0 & 0 & 0 & 0 & 0 & 0 \\
\hline $\begin{array}{l}\text { Male*Amer. Ind.I } \\
\text { Alas. Native }\end{array}$ & 0 & 0 & 0 & 0 & 0 & 0 & 0 & 0 & 0 & 0 \\
\hline $\begin{array}{l}\text { Female*Amer.Ind.I } \\
\text { Alas. Native }\end{array}$ & 0 & 0 & 0 & 0 & 0 & 8 & 8 & 0 & 10 & 0 \\
\hline Male*Asian & 0 & 0 & 0 & 0 & 0 & 0 & 0 & 0 & 0 & 0 \\
\hline Female*Asian & 0 & 0 & 0 & 0 & 0 & 0 & 0 & 0 & 0 & 0 \\
\hline Male*Black & 0 & 0 & 0 & 0 & 0 & 0 & 0 & 0 & 0 & 0 \\
\hline Female*Black & 0 & 0 & 4 & 0 & 0 & 0 & 0 & 0 & 0 & 0 \\
\hline Male*Hispanic & 0 & 0 & 0 & 0 & 0 & 0 & 0 & 0 & 0 & 0 \\
\hline Female*Hispanic & 0 & 0 & 0 & 0 & 0 & 0 & 4 & 0 & 6 & 0 \\
\hline Male*White & 0 & 0 & 0 & 0 & 0 & 0 & 0 & 0 & 0 & 0 \\
\hline Female*White & 0 & 0 & 0 & 0 & 0 & 6 & 0 & 0 & 6 & 0 \\
\hline Predicted Value & 827 & 833 & 837 & 839 & 841 & 844 & 847 & 849 & 855 & 864 \\
\hline
\end{tabular}

Note: Groups less than 5 represented by **** followed by exact $(n$

Race and Socioeconomic Status

As evidenced by this analysis, a pattern of negative impact on mathematics achievement across all three grades is evident for students who are in racial categories American Indian/Alaska Native, Hispanic/Latino, and Black/African American.

Similarly, students with lower economic status who are eligible for free or reduced lunch have been revealed as having significantly lower mathematics achievement than their higher economic status peers. These patterns warrant further investigation to 
discern if the race categories of American Indian/ Alaska Native, Hispanic/Latino and Black/African American are overrepresented in the lower socioeconomic group of students.

The Chi-Square goodness of fit value is a commonly used method of testing the association of variables. An assumed model of independence is evaluated against the observed data to determine if the null hypothesis (i.e., the number of observations of race at each level of SES is consistent with the expected frequencies in the distribution) should be rejected.

The distribution was evaluated at each grade level using the Chi-Square statistic and results are shown in Tables 22, 23, and 24. Table 22 reveals the grade 4 frequencies and illustrates the connection of the three negatively impacted race categories (American Indian/ Alaska Native, Hispanic/Latino and Black/African American) to overrespresentation in the lower socioeconomic status group. In addition, a White economic advantage becomes clear as this race category has much greater representation in the higher economic status group. The Chi-Square goodness of fit value for fourth grade is $\chi^{2}=2719.9$, allowing a confident rejection of the null hypothesis. Chi-square analyses for all three grade levels that follow have seven degrees of freedom and $p$ statistic set at 0.05 . 
Table 22

SES Expected Values and Population Frequencies by Race for Grade 4

\begin{tabular}{lrrr}
\hline Ethnic & & SES 0 & SES 1 \\
\hline American Indian/Alaskan Native & Frequency & 12 & 59 \\
& Expected & 37.9 & 33.1 \\
\hline Asian & Frequency & 172 & 164 \\
& Expected & 179.6 & 156.4 \\
\hline Black/African American & Frequency & 175 & 670 \\
& Expected & 451.7 & 393.3 \\
\hline Hispanic/Latino & Frequency & 369 & 1992 \\
& Expected & 1262 & 1099 \\
\hline White & Frequency & 4963 & 1964 \\
& Expected & 3702.7 & 3224.3 \\
\hline Two or More Races & Frequency & 105 & 178 \\
& Expected & 151.3 & 131.7 \\
\hline
\end{tabular}

Note: SES $0=$ not eligible for free/ reduced lunch, SES $1=$ eligible for free/reduced lunch; $p \leq 0.0001$

Grade 6 analysis results shown in Table 23 follow a pattern similar to fourth grade's, with the null hypothesis also being rejected. The Chi-Square value for this grade is $\chi^{2}=2,373.4$. 
Table 23

SES Expected Values and Population Frequencies by Race for Grade 6

\begin{tabular}{llrr}
\hline Ethnic & & SES 0 & SES 1 \\
\hline American Indian/Alaskan Native & Frequency & 31 & 52 \\
& Expected & 46.3 & 36.7 \\
\hline Asian & Frequency & 135 & 166 \\
& Expected & 167.9 & 133.1 \\
\hline Black/African American & Frequency & 186 & 593 \\
& Expected & 434.1 & 343.9 \\
\hline Hispanic/Latino & Frequency & 316 & 1637 \\
& Expected & 1089.5 & 863.5 \\
\hline White & Frequency & 4749 & 1778 \\
& Expected & 3641.3 & 2885.7 \\
\hline Two or More Races & Frequency & 96 & 140 \\
& Expected & 131.6 & 104.4 \\
\hline
\end{tabular}

Note: SES $0=$ not eligible for free/ reduced lunch, SES $1=$ eligible for free/reduced lunch; $p \leq 0.0001$

Analysis of grade 8 data shows agreement with grades 4 and 6 and once again the null hypothesis is rejected. Grade 8's Chi-Square statistic is $\chi^{2}=2,459.7$. To ensure anonymity, Native Hawaiian students were omitted from all Chi Square results since results revealed less than 10 students in some disagragated cells. 
Table 24

SES Expected Values and Population Frequencies by Race for Grade 8

\begin{tabular}{llrr}
\hline Ethnic & & SES 0 & \multicolumn{1}{c}{ SES 1 } \\
\hline American Indian/Alaskan Native & Frequency & 29 & 46 \\
& Expected & 43.1 & 31.9 \\
\hline Asian & Frequency & 166 & 171 \\
& Expected & 193.5 & 143.5 \\
\hline Black/African American & Frequency & 206 & 618 \\
& Expected & 473.1 & 350.9 \\
\hline Hispanic/Latino & Frequency & 447 & 1769 \\
& Expected & 1272.4 & 943.6 \\
\hline White & Frequency & 5338 & 1894 \\
& Expected & 4152.5 & 3079.5 \\
\hline Two or More Races & Frequency & 107 & 157 \\
& Expected & 151.6 & 112.4 \\
\hline
\end{tabular}

Note: SES $0=$ not eligible for free/ reduced lunch, SES $1=$ eligible for free/reduced lunch; $p \leq 0.0001$

These results demonstrate that the racial composition of the lower and higher socioeconomic status groups differs significantly from the hypothesized values that may occur by chance. Additionally, the race categories of Black/African American and Hispanic/Latino represent large subgroup sizes and point to a troubling pattern of lower socioeconomic status for these two groups that has been demonstrated in earlier sections of this research as negatively impacting mathematics achievement. In contrast, the category of being White is consistent in across grades as being disproportionately represented in the higher socioeconomic status group and White students benefit from the positive impact on mathematics achievement as revealed earlier in this paper. Data in Tables 22, 23, and 24 offer inarguable results that frequencies of race in the high and low categories of socioeconomic status vary significantly from those that would be expected by statistical chance. 
Analysis of Mathematics Subscores

A finer grained analysis of mathematics scores was conducted using the QUANTREG procedure in SAS to examine the results at the $0.25,0.5,0.75$, and 0.95 deciles for each sub-score available within the testing data. As seen in Tables 25, 26, and 27, being female has a negative consequence on nearly all mathematics strands for all grades at varying deciles. The reference group used in these analyses was male so this can also be considered conversely a positive consequence to males had the female gender been chosen as the reference group.

Since each sub-score represents only a portion of the total mathematics scaled score and areas of emphasis are different at each grade level (as seen in Table 6), direct comparisons are not possible across grades. What is revealed is a subtle pattern of lowered score in each strand for female students with only two exceptions; in sixth grade the strand of functions and algebra showed no significant interaction with gender; and in eighth grade both females and males evidenced point gains in the data and probability strand (although male gains were greater in three out of four quantiles).

Table 25

Grade 4 Mathematics Sub-scores by Gender

\begin{tabular}{lrrrr}
\hline Gender and Sub-score & Quantile & Quantile & Quantile & Quantile \\
& .25 & .50 & .75 & .95 \\
\hline Female*Number and Operations & -0.05 & -0.05 & -0.04 & -0.06 \\
Male*Number and Operations & 0 & 0 & 0 & 0 \\
Female*Geometry and Measurement & -0.33 & -0.14 & 0 & 0 \\
Male*Geometry and Measurement & 0 & 0 & 0 & 0 \\
Female*Functions and Algebra & -0.5 & -0.33 & -0.2 & -0.33 \\
Male*Functions and Algebra & 0 & 0 & 0 & 0 \\
Female*Data and Probability & -0.17 & -0.3 & -0.36 & -0.5 \\
Male*Data and Probability & 0 & 0 & 0 & 0 \\
\hline
\end{tabular}


Table 26

Grade 6 Mathematics Sub-scores by Gender

\begin{tabular}{lrrrr}
\hline Gender and Sub-score & Quantile & Quantile & Quantile & Quantile \\
& .25 & .50 & .75 & .95 \\
\hline Female*Number and Operations & 0 & 0 & -0.04 & -0.06 \\
Male*Number and Operations & 0 & 0 & 0 & 0 \\
Female*Geometry and Measurement & -0.33 & -0.14 & 0 & 0 \\
Male*Geometry and Measurement & 0 & 0 & 0 & 0 \\
Female*Functions and Algebra & 0 & 0 & 0 & 0 \\
Male*Functions and Algebra & 0 & 0 & 0 & 0 \\
Female*Data and Probability & 0 & -0.25 & 0 & 0 \\
Male*Data and Probablility & 0 & 0 & 0 & 0 \\
\hline
\end{tabular}

Table 27

Grade 8 Mathematics Sub-scores by Gender

\begin{tabular}{lrrrr}
\hline Gender and Sub-score & Quantile & Quantile & Quantile & Quantile \\
& .25 & .50 & .75 & .95 \\
\hline Female*Number and Operations & -0.11 & 0 & -0.07 & -0.16 \\
Male*Number and Operations & 0 & 0 & 0 & 0 \\
Female*Geometry and Measurement & -0.17 & -0.13 & -0.14 & 0 \\
Male*Geometry and Measurement & 0 & 0 & 0 & 0 \\
Female*Functions and Algebra & -0.04 & 0 & 0 & 0 \\
Male*Functions and Algebra & 0 & 0 & 0 & 0 \\
Female*Data and Probability & -0.26 & -0.2 & 0 & 0 \\
Male*Data and Probability & 0 & 0 & 0 & 0 \\
\hline
\end{tabular}




\section{CHAPTER 5}

\section{CONCLUSION}

Discussion of Results

A substantial body of educational research has focused on inequities in achievement based on student gender, race, and/or socioeconomic status. The last decade's focus on accountability has driven widespread data collection across the country in the form of student test scores, particularly in the areas of mathematics and reading (Jennings \& Rentner, 2006). Collected data have been used to highlight areas of inequality and track progress towards the goal of creating school systems in which all students have an opportunity to achieve (Darling-Hammond, 2010).

This study revealed differences in mathematics achievement in test results from one New England for grades 4, 6, and 6. The research considered the following questions:

- Are there meaningful differences between males and females in mathematics achievement in grades 4, 6, and 8 at the upper extremes of the distribution?

- How do race, socioeconomic status, and limited proficiency in English intersect with gender at the upper extremes of achievement?

\section{Major Findings}

An examination by central tendency of student achievement scores for mathematics in grades 4, 6, and 8 from a New England state's data showed no statistically significant differences by gender (Table 10). These results replicate those 
of the state testing agency, which also concluded that for testing year 2010-2011, no differences existed between male and female achievement in mathematics at these grade levels.

Using quantile regression methods to consider mathematics scores as a function of gender allowed analysis of precise regions in the achievement distribution. This methodology revealed that differences do exist in these data thus refuting a conclusion of no gender differences in mathematics achievement. Mathematics scores were divided into segments with intervals of 0.10 in each segment group, creating 10 groups beginning with the $0.09^{\text {th }}$ percentile and ending at the 0.99 percentile. Separate means of mathematics scores were estimated for each quantile and analyses of the predictive effects of gender were conducted and shown in Table 27.

\section{Grade Four}

Results for analyses of grade 4 data revealed a two-point advantage for females in mathematics scores at the lowest deciles of achievement while at the top range of achievement, a one-point advantage for females at the 0.69 and 0.89 deciles was found. For grade 4 students, girls' mathematics achievement in these data exceeded or equaled that of boys'.

\section{Grade Six}

In grade 6 data the evidence of female advantage in the lower test score deciles was gone and females in the high achieving $0.69,0.79$, and 0.89 deciles were consistently performing one-point lower than their male peers on this mathematics test. In the highest achieving student group at the 0.99 decile, female scores fell to a three- point disadvantage when compared with male peers. It is helpful to recall at this 
juncture in this analysis that these results can also be interpreted as a three-point advantage to males in the 0.99 percentile.

\section{Grade Eight}

Grade 8 analyses demonstrated a pattern of females having an advantage of one-point at the bottom of score ranges and a disadvantage of one-point at the top, beginning at the 0.59 decile and extending through the 0.99 . The center of the range revealed no gender difference in mathematics achievement for eighth grade students.

The results using quantile regression summarized in Table 28 lead to a rejection of the null hypothesis, there is no difference in mathematics achievement by gender in this population. Further, the point advantages and disadvantages revealed by quantile regression are potentially important for both males and females and may reflect impactful patterns of achievement, considering the substantial number of students $(31,858)$ represented by these data.

Table 28

Gender and Mathematics Achievement: Grades 4, 6, and 8

\begin{tabular}{l|rrrrrrrrrr}
\hline Quantiles & Quant. & Quant & Quant & Quant & Quant & Quant & Quant & Quant & Quant & Quant \\
& .09 & .19 & .29 & .39 & .49 & .59 & .69 & .79 & .89 & .99 \\
\hline Male Grade 4 & 0.000 & 0.000 & 0.000 & 0.000 & 0.000 & 0.000 & 0.000 & 0.000 & 0.000 & 0.000 \\
\hline Female Grade 4 & $\mathbf{2 . 0 0 0}$ & $\mathbf{2 . 0 0 0}$ & $\mathbf{2 . 0 0 0}$ & $\mathbf{1 . 0 0 0}$ & 0.000 & 0.000 & $\mathbf{1 . 0 0 0}$ & 0.000 & $\mathbf{1 . 0 0 0}$ & 0.000 \\
\hline Male Grade 6 & 0.000 & 0.000 & 0.000 & 0.000 & 0.000 & 0.000 & 0.000 & 0.000 & 0.000 & 0.000 \\
\hline Female Grade 6 & 0.000 & 0.000 & 0.000 & 0.000 & $\mathbf{- 1 . 0 0 0}$ & 0.000 & $\mathbf{- 1 . 0 0 0}$ & $\mathbf{- 1 . 0 0 0}$ & $\mathbf{- 1 . 0 0 0}$ & $\mathbf{- 3 . 0 0 0}$ \\
\hline Male Grade 8 & 0.000 & 0.000 & 0.000 & 0.000 & 0.000 & 0.000 & 0.000 & 0.000 & 0.000 & 0.000 \\
\hline Female Grade 8 & $\mathbf{1 . 0 0 0}$ & $\mathbf{1 . 0 0 0}$ & $\mathbf{1 . 0 0 0}$ & 0.000 & 0.000 & $\mathbf{- 1 . 0 0 0}$ & $\mathbf{- 1 . 0 0 0}$ & $\mathbf{- 1 . 0 0 0}$ & $\mathbf{- 1 . 0 0 0}$ & $\mathbf{- 1 . 0 0 0}$ \\
\hline
\end{tabular}

Figure 7 shows the results from graphing mathematics scores on the gender female for grades 4,6 , and 8 . The $y$-axes show the gender effects while the $\mathrm{x}$-axes are the percentiles across the distribution. The solid lines are the estimates for the effect of being female at each decile. 


\section{Grade Four}

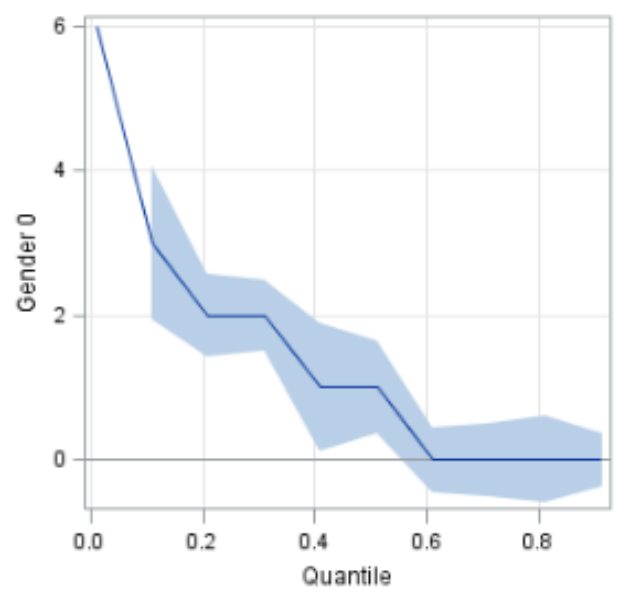

\section{Grade Six}
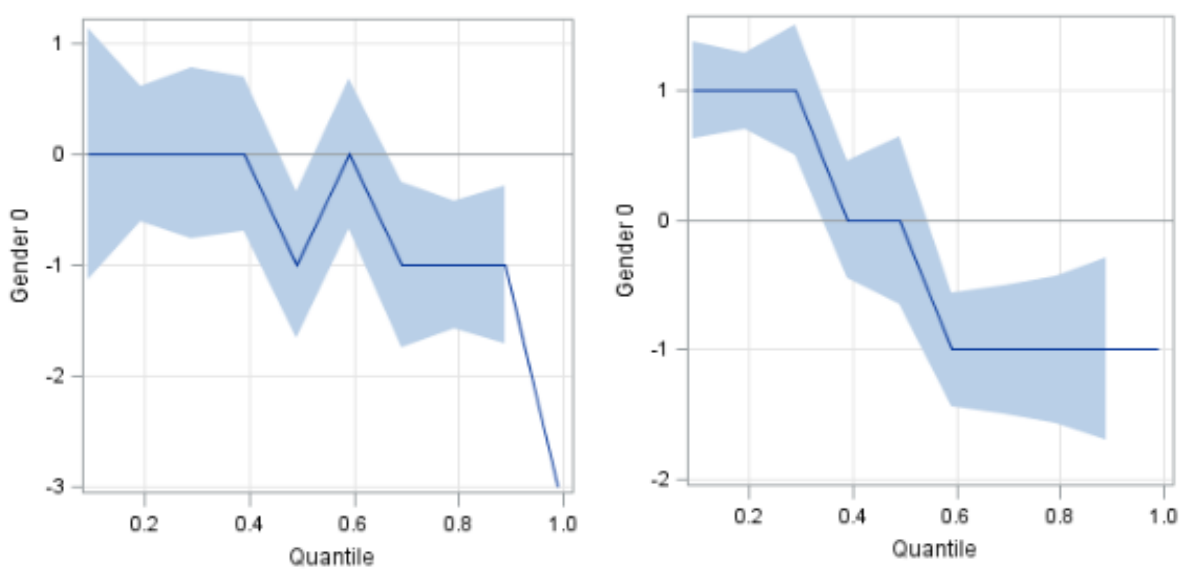

Figure 7. The effects of being female on mathematics achievement across the distribution in grades 4,6 , and 8. Note: Line is quantile regression estimate of gender effect for different percentiles, grey shading is the confidence interval. 


\section{The Impact of Socioeconomic Status}

In these data, socioeconomic status, race, and limited proficiency in English intersected with gender and mathematics achievement at specific deciles of the distribution in ways that varied across grades. Having higher economic status (as defined by non-participation in a free or reduced lunch program) offered a notable (additional eight to twelve-points) advantage affecting all students in the fourth grade distribution. There was no interaction between socioeconomic status and covariate gender in the fourth grade population.

Being in the student group who did not qualify for free or reduced lunch offered a significant point advantage to males and females in grade 6 as well, ranging across the distribution from an additional 10- to 12-points in test scores when considering variable SES and achievement in mathematics. With the addition of covariate gender to the model, a four-point disadvantage to sixth grade girls from families with higher income status is found at the 0.99 decile of achievement.

In the population of fourth grade students, the impact of economic status showed no interactions with gender; in other words, boys' and girls' mathematics achievement were affected by lower/higher economic status similarly. At grade 6 in these data, SES begins to differentially affect males and females at the highest level of achievement in these data, giving males who are higher economic status a four-point advantage over females with the same economic status (or -4 points to females).

Grade 8 results for SES and mathematics achievement also showed point advantages to students with higher economic status which ranged from six to eightpoints across deciles, a lessening of advantage from that found in the student groups in 
grades 4 and 6 but still highly significant. Remembering that these point advantages can also be interpreted as point disadvantages to students who live in lower economic households is helpful here. Some research evidence exists showing the effect of socioeconomic status as measured by free/reduced lunch status weakens in upper grades, and it has been theorized that financial paperwork that families are required to complete in order to qualify for free lunch is less likely to be transmitted by older students (McLoyd, 1998). Therefore the reduction in correlation at grade 8 may a function of how socioeconomic status is defined in these data.

\section{The Impact of Limited Proficiency in English}

Analysis of mathematics achievement with foci on gender and LEP status revealed that students who are labeled learners of English language face negative consequences on mathematics achievement scores in these testing data. For all student groups in this population, no interactions occurred with gender, allowing a conclusion that status or non-status as an English language learner affected both genders similarly in grades 4,6 , and 8 .

In grade 4 , the effects on mathematics scores ranged from -5 to -11.29 -points for both genders. At the 0.25 quartile, students who are not categorized as limited in English proficiency gained an additional nine-points over peers receiving their first year of support as English language learners (LEP 1). Analyses of sixth grade mathematics scores by covariates gender and LEP revealed increasingly negative consequences to students who are English language learners at this grade level. Beginning at the lowest range of scores, these students were 14- to 15-points lower scoring than their more English proficient peers. The data from analyses of grade 8 
mathematics scores with covariates gender and LEP status revealed an advantage for students not categorized with limited proficiency in English of 7.03-points at the 0.75 quantile only. The negative effects of status as an English language learner found in grades 4 and 6 were not evident at significant levels for the population of grade 8 students. It bears noting that the percentage of students with status as a first year English language learner decreases in these data with $6.4 \%$ at grade 4, to $3.2 \%$ at grade 8 (see Table 3 ).

\section{The Impact of Race}

Analyses of the dependent variable mathematics scaled score with covariates gender and race revealed statistically significant patterns in achievement at each grade

level in these data. For the purpose of analysis, all racial categories were maintained as defined by the state department of education. These student groups by race were American Indian/Alaskan Native, Asian, Black/African American, Hispanic/Latino, Native Hawaiian/Pacific Islander, White, or Two or More Races. Students who were not identified by race in these data were omitted in this aspect of the model only.

In each grade examined, racial groups of smaller student representation evidenced significant findings. Although results for groups with small representation are difficult to generalize, specific findings concerning achievement and minority status may indicate areas for future research.

For students in fourth grade in this population, there was a negative consequence of being American Indian/Alaskan Native that was most significant at the lowest levels of achievement. Since the group of fourth graders categorized as American Indian had only 71 students, it is difficult to draw meaningful conclusions 
from these results. A closer examination of significant results within this subgroup found only 19 students at the 0.09 decile, 11 students at 0.19 decile, 10 students at 0.29 decile, and five students at the 0.39 decile. The small numbers of American Indian/Alaskan Native students make interpretation difficult but may point to an area for future research.

Being Black/African American was represented by an $n$ of 845 students, and the scores of these students were negatively impacted through the entire range of achievement. Hispanic/Latino students with a robust $n$ of 2361 students also had negatively impacted scores throughout the entire range, as shown in Table 19. The consequence of being White (6,297 students) was positive or neutral in fourth grade and, along with being categorized as Asian (336 students), added the most benefit to those scores in the highest scoring 0.99 decile. The racial category Native Hawaiian/Pacific Islander had a mere nine students in fourth grade, and so no patterns of mathematics achievement are reported for this group of students.

The use of quantile regression methodology revealed negative consequences at all levels of mathematics achievement for fourth grade students who were either Black or Hispanic. Given the large number of students represented by these data, these patterns present convincing evidence that membership in these two racial categories translated into significantly lower mathematics achievement on this test for this population. Interactions between being female and being American Indian, Asian, Black, Hispanic or White occurred in the fourth grade data, and in the highest achieving aspect of the distribution of 0.99 decile, produced negative point consequences for these students as seen in Table 19. 
Probing data for student mathematics scores in grade 6 with covariates gender and race revealed similar patterns for racial status as those found in grade 4 in members labeled Black/African American or Hispanic/Latino. All deciles evidenced a negative impact on achievement for these two groups as displayed in Table 20.

In results for grade 6 as in grade 4, both American Indian/Alaskan Native and Native Hawaiian/Pacific Islander were groups with small representation in these data with 83 students and 11 students respectively. Although results in Table 20 revealed negative impacts to achievement for members in these groups, their small $n$, combined with the parceling out of students across 10 deciles in the distribution, make results difficult to interpret with confidence.

Interactions between being female and labeled Asian produced a negative impact on the 0.99 decile of mathematics achievement in grade 6 , which can also be interpreted as an advantage to being Asian and male at this decile. Being White and female also had a positive interaction of adding 11-points at the 0.99 decile of the distribution. Probing the data revealed that there were 11 White females and 17 White males at this decile.

Analyses were conducted for eighth grade scores with gender, mathematics achievement and race as variables. Patterns for students with status as Black/African American or Hispanic/Latino remained similar to those found at grades 4 and 6 with the notable exception of the 0.99 percentile. In grade 6, students labeled Black/African American had a -16 point consequence to achievement and Hispanic/Latino students had -17 points. In eighth grade, the negative effect on the highest achieving students has disappeared and there was no consequence of race for either group as seen in 
Table 21. A check of the data at a finer level revealed that there were only eight Hispanic students at this decile and no students labeled Black/African American. Interestingly, the category of White provided no benefit to students in the eighth grade data across any decile of the distribution for the first time in these data. Being White and a female interacted to provide a six-point advantage at deciles 0.59 and 0.89 , and being female and Hispanic also provided four and six-point advantages at the 0.69 and 0.89 deciles respectively, seen in Table 21.

Implications for the Field of Education

In recent years the forces of educational policy have placed great emphasis on measuring student achievement, usually through the use of some test. Results from these tests are used to judge the success of teachers, schools, districts, and even whole states towards some specified standards of achievement for students. In the cases of NCLB and more recently Race to the Top policies, these standards are incrementally raised to higher levels for subgroups of students with the goal of increasing achievement for all learners.

A commonly used method of analyzing achievement scores in educational research has been Ordinary Least Squares (OLS) regression (Reeves \& Lowe, 2006). OLS regression has been used to understand the relationship between a dependent variable such as student achievement in a content area, and predictor variable(s) such as socioeconomic or special needs status, by comparing the means conditional on treatment status and other variables.

If mean regression estimates were the single method of analysis used in this research, a conclusion would have been reached that no relation between gender and 
mathematics achievement scores exists. Through the use of quantile regression methodology, a more precise explanation of factors affecting achievement at all levels of the data has been achieved. The fine level of explanatory power enabled through quantile regression offers a robustness check to linear regression methods as evidenced in this research, and allows significant differences to be identified at multiple points in the distribution. Researchers using OLS regression to analyze large data sets may want to begin using quantile regression methodology as a check of their findings. If OLS methods reveal no difference in mean achievement (as in the present case) and quantile regression also finds no differences across the distribution, then practitioners of educational researcher can be assured that results are truly robust for all students in the distribution. Implications for the Fields of Science, Technology, and Engineering

Recently, President Obama launched the campaign Educate to Innovate, with the stated goal of increasing American students' participation in science, technology, engineering, and mathematics (STEM) careers (Educate to Innovate, 2012).

Supporting educational paths leading to STEM careers has been described as critical to the country's ability to compete economically in a global society (National Governors Association, 2009; Toulmin \& Groome, 2007). Female underrepresentation in STEM careers is therefore considered especially important to the future of the United States, since the best and brightest from both genders are needed in the STEM talent pool (United States Department of Labor, 2007).

Analyses of students' achievement in mathematics at various levels beyond central tendencies are informative when considering issues of gender equity and 
entrance into STEM paths. A body of research supports the conclusion that mathematics functions as a "critical filter" to entrance into college and career, especially as it relates to STEM pathway (Miller \& Kimmel, 2010; Xie \& Shauman, 2003). Research suggests students who enter careers in science, technology, engineering, and mathematics begin the journey in elementary school and overwhelmingly come from those with high achievement in mathematics (Berryman, 1983; Tai, Liu, Maltese, \& Fan, 2006). Since mathematics achievement acts as a part of the conduit for students' STEM school-to-career path, and gender equity in participation is a desired goal, the identification of gender inequities in math achievement at the highest levels of achievement is revelatory. Quantile regression offers a complement to means-based methodologies and allows a complete description of the distribution, including the highest areas of mathematics achievement.

In this study, differences in achievement in one northeastern states' testing data were described. No gender differences at the highest levels of mathematics achievement were found in the fourth grade population, but by the time students were in grades 6 and 8, patterns appeared in the data privileging boys at the highest levels of achievement. Although not large, the differences revealed of one, two, or three-points, are potentially impactful. Research tells us these levels are where many future STEM students reside and lowered female achievement at grades 6 and 8 may foretell increasing disparities as students progress to higher grade levels.

Within these results also are troubling patterns related to achievement for students with lower socioeconomic status and/or who are members of Hispanic/Latino, Black/African American, or American Indian/Alaskan Native racial groups. Each of 
these subgroups was impacted, especially in the higher achieving levels of mathematics scores, and in all cases the impact was lowered mathematics achievement. Although interactions with these subgroups and the variable gender did not reveal conclusive and consistent patterns, the lowered scores of males and females together in these subgroups should be concerning to those seeking greater representation in the STEM fields of study.

The problem of poor achievement for those students who are racial minorities or disadvantaged economically is a challenge to policymakers and has complex social causes (Brown-Jeffy, 2009). When subgroups of a population are underrepresented in the pipeline leading to careers in science, technology, engineering, and mathematics, there is a cost to society in both the national and global economies (Toulmin \& Groome 2007). The results in this research demonstrate patterns of unequal achievement that point towards a systemic problem for these students that may be negatively impacting future equal representation of membership in the STEM fields. Implications for School Practice and Individual Teachers

The results of this research demonstrate a gendered pattern of achievement in mathematics for students in grade 4, 6, and 8 in this population. These data provide evidence of girls' lowered scores in the highest achieving tail of the distribution beginning in sixth grade. Remembering that the testing instrument was administered in October 2010 and designed to measure prior year achievement, the findings indicate an area of concern for practitioners that begins at the elementary school level.

If girls are beginning to show statistically significant deficits in high achievement as early as fifth grade, it is not a great leap to conclude that these patterns 
are being formed by earlier experiences. Although parent education, family attitudes, and experiences prior to school entry have been associated with mathematics achievement (Christenson, Rounds, \& Gorney, 1992), variables that are within the purview of schools and classrooms should take a central position in the discussion of mathematics, high achievement, and gender.

Affective variables such as students' beliefs and attitudes have been linked to achievement in mathematics (McLeod, 1992) and are factors to consider at the school level as possible contributors to gender differences in these data. Girls have been found to be less likely than boys to attribute their success in mathematics to their ability, while boys are unlikely to attribute failure to their own lack of capacity (Peterson \& Fennema, 1985; Seegers and Boekaerts, 1996). Higher confidence of boys when facing mathematical tasks has been documented in research, and expectations for success influence achievement (Eccles, 1985; Vermeer, Boekaerts, \& Seegers, 2000) and are possible influences affecting these research results.

Schools and individual teachers concerned with equity in mathematics achievement may want to consider their roles in contributing to student attributes surrounding mathematics. "We get interested in what we are good at," stated Jerome Bruner (p 118, 1978). Research suggests teachers have opportunities for improving mathematics performance at the elementary level by implementing instructional methods geared towards increasing student self-efficacy (Schunk, 1981). Setting clear goals that allow both teacher and student to attend to problem solving successes (Siegel \& McCoach, 2007; Schunk, 1984) and structuring opportunities for students to watch others like themselves grapple and succeed on mathematical tasks can 
positively influence students' feelings about themselves and their achievements (Schunk, 1981).

Among the realities of classrooms are the everyday lives of teachers as they work to help students reach their highest potential within the context of a complex, demanding environment (Fullan, 2001). Actual change in teaching practice requires possible use of new teaching resources, new teaching approaches, and change in teacher beliefs (Fullan, 2001).

Teachers concerned with optimal achievement for both boys and girls may want to consider their own attributions in the mathematics classroom. Some research has shown that teachers' beliefs about boys' and girls' mathematics achievement differ in important ways and that teachers see boys' success as being due to high ability while females' failure as due to lack of effort (Fennema, Peterson, Carpenter, \& Lubinski, 1990). These attributions are significant as they impact teachers' expectations and behaviors as well as future expectation about children (Graham, 1984).

Jones and Dindia's (2004) conducted a meta-analysis of research around the topic of gender equity in the classroom and revealed a pattern of more frequent teacher interactions with boys than girls, as well as differences in engagement with students that varied by teacher gender. Practitioners may wish to consider whether their own interactions with boy students differ in quality and quantity from that of girls', and whether the social context of their classroom supports high achievement for both genders. 
Changes to mathematics teaching in response to research findings may range from minor to major since teachers, like other professionals, vary widely in skill, commitment, and initiative (Hill, Rowan \& Ball, 2005). A key challenge when improving mathematics education is what has been described as the deficit in US teachers' knowledge surrounding mathematics content (Ma, 1999). Theorists from John Dewey to Lee Shulman have reasoned that teachers' responsibilities for presenting different types of subject matter require different knowledge (Hill, Rowan \& Ball, 2005). Researchers argue that student progress is hindered not only by adherence to tired methods but also by teachers' lack of understanding of mathematics at a deep level (Hill, Rowan \& Ball, 2005, Ma, 1999).

If more teacher knowledge correlates with more knowledge for students, it stands to reason that one axis of response to this research may be a renewed goal of improving teachers' deep understanding of mathematics. Continued professional development supporting teachers' understandings of mathematical content is associated with higher student achievement (Schoen, Cebulla, Fin, \& Fi, 2003) and may have the benefit of scaffolding mathematics achievement for students of both genders. Wayne and Youngs (2003) report evidence that there exists a relationship between teachers with higher college ranking and their students' achievement. Besides supporting ongoing professional development for existing teachers, this finding lends credence to the idea of rigorous standards for students entering the teaching profession pipeline. 


\section{Limitations of the Study}

The results of these analyses reflect findings from just one student population from one state in the northeast. The population was not random and so caution must be used when interpreting results of this research. Students in the population represent all fourth, sixth, and eighth grade students in the state but do not represent "every student" by the nature of the way the data were collected. Therefore, results may be of interest to other northeastern states using the same achievement test, but are not generalizable outside the state examined. Additionally, the exact mechanisms contributing to the effects found through these analyses are unknown.

All foci of this research have been to reveal whether achievement gaps exist by gender in mathematics achievement. One limitation of this examination is the narrow picture painted by these results that are static and provide only a small slice of total student learning for these children. Another valid critique is that studies such as this may support deficit thinking about females, racial minorities, or students with lower socioeconomic status. The use of one test to stand for mathematics achievement is dangerous in itself and so interpretation of these tests should offer the greatest possible explanatory power for all students. In our current era of accountability, these snapshots are frequently the only tools emphasized for revealing important patterns in learning, access, and equity and therefore should be complete and fine-grained so that all groups in the distribution are represented.

\section{Suggestions for Future Research}

This study offers a model for those seeking a fuller picture of student achievement than ordinary regression models provides. One interesting outcome of 
analyses through quantile regression methods has been the finding of a girl advantage at the lower end of the achievement distribution. Low performance for any subgroup of students has far reaching social and economic consequences including the direct and easily measurable costs of special education services, which are assigned to more males than females (Wehmeyer, \& Schwartz, 2001). If the lowest achieving boys are potentially being ignored by a linear regression analysis, those with an interest in moving students from failing to proficiency may consider employing quantile regression statistics to probe mathematics achievement results in finer detail for males.

Future researchers may wish to conduct an examination of state data for students in grade nine and beyond to determine if lowered female achievement at grades six and eight may foretell increasing disparities as students advance through grade levels. In doing so, patterns revealed may further illuminate the role of gender as students move through the STEM pipeline. Other areas for potential research include further analyses of mathematics achievement by subgroups in upper grades using race and socioeconomic status as covariates to determine if the consequential patterns found in the current study remain consistent, diminish, or escalate.

\section{Summary}

This study found disparities in mathematics achievement and answered each research question. The data provide impactful results that add to the literature surrounding mathematics achievement and gender. The issue of female representation at the highest levels of achievement has repercussions for STEM fields and all educational stakeholders. 


\section{Final Comments}

It seems evident that results relying on central tendencies of group achievement do not necessarily describe the real-worlds of students across the range of mathematics ability. In this study it has been shown that gender differences that were not captured with ordinary least squares regression were indeed found at both low and high achieving ends of the distribution. These findings will be of interest to educational stakeholders including the state department of education from which these data hail and other states also using the same instrument. Additionally, individual districts may wish to disaggregate testing data to specify areas of need not previously identified, and address student achievement inequities through targeted professional development of teachers.

In our current climate of testing accountability, too often the focus of teacher attention is moving low achievers to proficiency to avoid authority sanctions. In this adequacy versus equity model, one unintended consequence may be diminished attention to the students who are our higher achievers (Payne-Tsoupros 2010). Classroom teachers as change-agents will hopefully consider these results when reflecting on professional practices with consideration of their role in closing gaps for all learners. 


\section{Appendix A}

\section{DATA REQUEST}

December 8, 2011

Commissioner

Department of Education

\section{Dear Commissioner:}

The study requires the 2010 mathematics data for ALL students in grades 4, 6, and 8 . In order to submit the dissertation proposal to the Institutional Review Board, Laura Falvey must have a letter granting access and permission to use these data.

The dissertation proposal that includes the permission letter will be reviewed by the Institutional Review Board. The management and use of the data and resulting analysis and findings will be handled in accordance with the federal guidelines for the protection of human subjects. Thus, no school districts, schools, or individual students would be identified. No disaggregated groups of ten or fewer students will be identified. The requested data set would not include student names. The specific fields required to complete the study are attached. The dataset would be kept secure at all times using password protection for the files and computer on which the analysis is completed. Given the experience of her doctoral committee in handling datasets, I am confident that the data and results of this study will be handled with the utmost of professional care.

The purpose of the study is to examine patterns in performance associated with gender and high mathematics achievement. The proposed research will use quantile regression methodology to examine mathematics achievement as a function of gender and other student characteristics to reveal if differences exist in the top percentiles of achievement densities. The use of a quantile model will enable the capture of any percentile of the distribution to reveal changes by student characteristics. This statistical method allows a more accurate picture of achievement in mathematics than can be revealed by means-based methods.

The results of this study would provide the Department of Education with insights into the phenomenon of gender differences in the highest levels of mathematics achievement. Additionally, results may help focus teachers and other stakeholders on any discrepancies among students with the highest levels of mathematics achievement.

Thank you for your consideration and I look forward to hearing your decision. If there are any further questions related to this request, please contact me by email.

Sincerely,

Professor, School of Education 
Appendix A (Continued)

2010 Mathematics Data for Grades 4, 6 and 8 (testing years)

For all districts and schools:

SASID for all students in grades 4,6 , and 8 (names removed)

School/District codes

Raw scores and Scaled Scores:

Overall

Numbers \& Operations

Geometry \& Measurement

Functions \& Algebra

Data, Statistics \& Probability

Proficiency Levels for each student

Student Questionnaire Data—Mathematics:

Questions 11-23

Demographic Data:

Gender

Male

Female

Not Reported

Race/Ethnicity

Hispanic or Latino

Not Hispanic or Latino

American Indian or Alaskan Native

Asian

Black or African American

Native Hawaiian or Pacific c Islander

White

Two or more races

No Race/Ethnicity Reported

LEP Status

Current LEP student

Former LEP student - monitoring year 1

Former LEP student - monitoring year 2

All Other Students

SES

Economically Disadvantaged Students

All Other Students 
Appendix B

Depth Of Knowledge Levels (DOK)

Descriptors for Mathematics

\begin{tabular}{|l||l||}
\hline \hline $\begin{array}{l}\text { Level 1 (Recalling } \\
\text { Information and } \\
\text { Carrying Out Simple } \\
\text { Procedures) }\end{array}$ & $\begin{array}{l}\text { This level requires the recall of a fact, definition, term, or } \\
\text { simple procedure; the application of a formula; or the } \\
\text { performance of a straight algorithmic procedure. Items at this } \\
\text { level may require students to demonstrate a rote response. }\end{array}$ \\
\hline \hline Level 2 (Skill/Concept) & $\begin{array}{l}\text { This level requires mental processing beyond that of a simple } \\
\text { habitual response. These items often require students to make } \\
\text { some decisions about how to approach a problem. }\end{array}$ \\
\hline $\begin{array}{l}\text { Level 3 (Strategic } \\
\text { Thinking, Reasoning, } \\
\text { Planning, Drawing } \\
\text { Conclusions, and } \\
\text { Using Concepts and } \\
\text { Evidence) }\end{array}$ & $\begin{array}{l}\text { This level requires students to develop a plan or sequence of } \\
\text { steps. These items are more complex and abstract than the } \\
\text { items at the previous two levels. These items may also have } \\
\text { more than one possible answer and may require students to use } \\
\text { evidence, make conjectures, or justify their answers. }\end{array}$ \\
\hline \hline
\end{tabular}

Note. Adapted from "New England Common Assessment Program, 2010-2011, Technical Report" Reliability and Standard Errors of Measurement, p.10. Retrieved October 28, 2011 from

http://www.ride.ri.gov/assessment/DOCS/NECAP/Reports_Results/201011_NECAP_Math-Reading-Writing_Tech_Report.pdf 


\section{Bibliography}

Abidin, R. R. (1971). Elementary school retention: An unjustifiable, discriminatory and noxious educational policy. Journal of School Psychology, 9(4), 410-417. Retrieved on October 2, 2011 from http://psycnet.apa.org/psycinfo/1972-21807$\underline{001}$

American Association of University Women, (1992). How schools shortchange girls. A study of major findings on girls and education. Report: ED339674. Retrieved on August 8, 2005 from http:/www.aauw.org/learn/research/upload/hssg.pdf

American Educational Research Association, American Psychological Association, National Council on Measurement in Education, Joint Committee on Standards for Educational, \& Psychological Testing (US). (1999). Standards for educational and psychological testing. American Educational Research Assn.

Astin, A. W., \& Astin, H. S. (1992). Undergraduate science education: The impact of different college environments on the educational pipeline in the sciences. final report. Retrieved on April 4, 2011 from http://www.seaphe.org/pdf/astin.pdf

Baker, F. B. (2001). The basics of item response theory. Retrieved May 11, 2012, from: http://echo.edres.org:8080/irt/baker/chapter1.pdf

Bandura, A. (1993). Perceived self-efficacy in cognitive development and functioning. Educational Psychologist, 28, 117-148.

Becker, J. (1981). Differential treatment of females and males in mathematics classes. Journal for Research in Mathematics Education, 12, 40-53.

Benbow, C. P., \& Stanley, J. C. (1980). Sex differences in mathematical ability: Fact or artifact?. Science, 210(4475), 1262-1264.

Berryman, S. (1983). Who will do science? Trends, and their causes in minority and female representation among holders of advanced degrees in science and mathematics. A special report. Retrieved October 12, 2011 from http://www.eric.ed.gov/PDFS/ED245052.pdf

Brown-Jeffy, S. (2009). School Effects: Examining the Race Gap in Mathematics Achievement. Journal of African American Studies, 13(4), 388-405.

Bruner, J. S. (1966). Toward a theory of instruction Belknap Press.

Carpenter, T. P., Fennema, E., \& Franke, M. L. (1996). Cognitively guided instruction: A knowledge base for reform in primary mathematics instruction. The Elementary School Journal, 97(1), 3-20. 
Christenson, S. L., Rounds, T., \& Gorney, D. (1992). Family factors and student achievement: An avenue to increase students' success. School Psychology Quarterly, 7(3), 178.

Cronbach, L. (1951). Cronbach's alpha internal consistency, coefficient alpha and the internal structure of tests. Psychometrika, 16, 297-334.

Darling-Hammond, L. (2010). America's commitment to equity will determine our future. Phi Delta Kappan, 91(4), 8-14.

Developing, A., Administering, B., \& Takers, D. I. T. (2002). Code of fair testing practices in education. Retrieved May 18, 2012 from http://157.181.12.10/letoltesek/tudomanyos testuletek/dokumentumok/Code\%20 of $\% 20$ Fair $\% 20$ Testing $\% 20$ Practices $\% 20$ in $\% 20$ Education.pdf

Duhachek, A., Coughlan, A. T., \& Iacobucci, D. (2005). Results on the standard error of the coefficient alpha index of reliability. Marketing Science, 24(2), pp. 294301 .

Dunteman, G. H., \& And Others. (1979). Race and sex differences in college science program participation. ( No. RTI-22U-1570). http://www.eric.ed.gov/PDFS/ED199034.pdf

Dwyer, C. A. (1973). Sex differences in reading: An evaluation and a critique of current theories. Review of Educational Research, 43(4), pp. 455-467. Retrieved on August 4, 2005 from http://0- http://0www.jstor.org.helin.uri.edu/stable/10.2307/1170076

Eccles, J. (1985). Sex differences in achievement patterns. Psychology and Gender, , 97-132.

Eccles, J. S., \& Blumenfeld, P. (1985). Classroom experiences and student gender: Are there differences and do they matter. Gender Influences in Classroom Interaction, 79-114. Retrieved April 8, 2005 from http://www.rcgd.isr.umich.edu/garp/articles/eccles85b.pdf

Emmons, M. E., \& Jacklin, C. N. (1974). The psychology of sex differences. Stanford University Press, California.

Entwisle, D. R., Alexander, K. L., (1993). Entry Into School: The Beginning School Transition and Educational Stratification in the United States Annual Review of Sociology, Vol. 19, (1993), pp. 401-423 Retrieved October 18, 2006 from Article Stable URL: http://0-www.jstor.org.helin.uri.edu/stable/2083394 
Entwisle, D. R., Alexander, K. L., \& Olson, L. S. (1994). The gender gap in math: Its possible origins in neighborhood effects. American Sociological Review, 59, 822838.

Felson, R., \& Trudeau, L. (1991) Gender differences in mathematics performance. Social Psychology Quarterly, 54, 113-126.

Fennema, E. (1979). Women and girls in mathematics-Equity in mathematics education. Educational Studies in Mathematics, 10(4), 389-401.

Fennema, E., Carpenter, T. P., Jacobs, V. R., Franke, M. L., \& Levi, L. W. (1998). A longitudinal study of gender differences in young children's mathematical thinking. Educational Researcher. 27 (5), 6-11.

Fennema, E., Peterson, P. L., Carpenter, T. P., \& Lubinski, C. A. (1990). Teachers' attributions and beliefs about girls, boys, and mathematics. Educational Studies in Mathematics, 21(1), 55-69. Retrieved May 1, 2005 from http://0www.jstor.org.helin.uri.edu/stable/10.2307/3482218

Fennema, E., \& Sherman, J. (1977). Sexual stereotyping and mathematics learning. Arithmetic Teacher, 24, 369-372. Retrieved February 18, 2005 from http://0www.jstor.org.helin.uri.edu/discover/10.2307/41189301 ?uid $=33248 \&$ uid $=37398$ 88\&uid $=2134 \&$ uid $=2 \&$ uid $=70 \&$ uid $=3 \&$ uid $=67 \&$ uid $=33247 \&$ uid $=62 \&$ uid $=3739$ $\underline{256 \& \text { sid }=21101332953603}$

Fennema, E., \& Sherman, J. (1978) Sex-related differences in mathematics achievement and related factors: A further study. Journal for Research in Mathematics Education, 9, 189-203. Retrieved February 21, 2005 from http://0www.jstor.org.helin.uri.edu/stable/10.2307/748997

Friedman, L. (1989). Mathematics and the gender gap: A met-analysis of recent studies on sex differences in mathematical tasks. Review of Educational Research, 59(2), 185. Retrieved February 4, 2007 from http://0www.jstor.org.helin.uri.edu/stable/pdfplus/1170414.pdf?acceptTC=true

Fullan, M. G. (2001). The new meaning of educational change. $3^{\text {rd }}$ edition, Teachers College Press, New York.

Fuson, K. C., Wearne, D., Hiebert, J. C., Murray, H. G., Human, P. G., Olivier, A. I., . . . Fennema, E. (1997). Children's conceptual structures for multidigit numbers and methods of multidigit addition and subtraction. Journal for Research in Mathematics Education, 130-162.

Geary, D. C., Saults, S. J., Liu, F., \& Hoard, M. K. (2000). Sex differences in spatial cognition, computational fluency, and arithmetical reasoning. Journal of Experimental Child Psychology, 77(4), 337-353. 
Good, T. (1981). Teacher expectations and student perceptions: A decade of research. Educational Leadership, 38, 415-422.

Gowlland, C., Xiao, Z., \& Zeng, Q. (2009). Beyond the central tendency: Quantile regression as a tool in quantitative investing. The Journal of Portfolio Management, 35(3), 106-119.

Graham, S. (1984). Teacher feelings and student thoughts: An attributional approach to affect in the classroom. The Elementary School Journal, 85(1), 91-104. Retrieved on May 1, 2007 from http://0www.jstor.org.helin.uri.edu/stable/pdfplus/1001621.pdf?acceptTC $=$ true

Gurian, M. (1998). The wonder of boys: What parents, mentors, and educators can do to shape boys into exceptional men. New York: Henry Holt and Company.

Hall, C. W., Davis, N. B., Bolen, L. M., \& Chia, R. (1999). Gender and racial differences in mathematical performance. The Journal of Social Psychology, 139(6), 677-689.

Halpern, D. F., \& LaMay, M. L. (2000). The smarter sex: A critical review of sex differences in intelligence. Educational Psychology Review, 12(2), 229-246. Retrieved January 30, 2007 from http://www.dppd.utcluj.ro/stud/the $\% 20$ smarter $\% 20$ sex_a $\% 20$ critical $\% 20$ review $\%$ 20of $\% 20$ sex $\% 20$ differences $\% 20 \mathrm{in} \% 20$ inteligence_2000.pdf

Hanna, D. G. (2003). Reaching gender equity in mathematics education. The Educational Forum, 67(3) 204-214. Retrieved July 8, 2005 from http://dipmat.math.unipa.it/ grim/Jhanna.PDF

Hao, L. \& Naiman. D. Q., (2007). Quantile Regression (Quantitative Applications in the Social Sciences, no. 149). Thousand Oaks, CA: Sage.

Hemphill, F. C., \& Vanneman, A. (2011). Achievement gaps: How Hispanic and white students in public schools perform in mathematics and reading on the national assessment of educational progress. statistical analysis report. NCES 2011-459. National Center for Education Statistics.

Hill, H. C., Rowan, B., \& Ball, D. L. (2005). Effects of teachers' mathematical knowledge for teaching on student achievement. American Educational Research Journal, 42(2), 371-406.

Ho, A. D. (2008). The problem with "proficiency": Limitations of statistics and Policy under no child left behind. Educational Researcher, 37(6), 351. 
Hoff, D. J. (2008). More schools facing sanctions under NCLB. Education Week. Retrieved August 1, 2009, from http://www.edweek.org/ew/articles/2008/12/18/16ayp.h28.html

Hyde, J. S. (1990). Meta-analysis and the psychology of gender differences. Signs, 16(1), 55-73. Retrieved on February 20, 2007 from http://0web.ebscohost.com.helin.uri.edu/ehost/pdfviewer/pdfviewer?vid=4\&hid=24\&sid $=26189305-44 \mathrm{~d} 4-4 \mathrm{f} 28$-aea4-01fd4f531995\%40sessionmgr13

Hyde, J. S., Fennema, E., \& Lamon, S. J. (1990). Gender differences in mathematics performance: A meta-analysis. Psychological Bulletin, 107(2), 139. Retrieved on March 18, 2007 from http://0web.ebscohost.com.helin.uri.edu/ehost/pdfviewer/pdfviewer?vid=3\&hid= 24\&sid=ebbb70d3-ba72-4411-af7a-b93b323de23d\%40sessionmgr

Hyde, J. S., Lindberg, S. M., Linn, M. C., Ellis, A. B., \& Williams, C. C. (2008). Gender similarities characterize math performance. Science, 321(5888), 494-495. Retrieved October 1, 2011 from http://dericbownds.net/uploaded_images/hyde.pdf

Jacklin, C. N. (1989). Female and male: Issues of gender. American Psychologist, 44(2), 127. Retrieved on August 10, 2010 from http://0web.ebscohost.com.helin.uri.edu/ehost/pdfviewer/pdfviewer?vid=3\&hid=24\&sid $=$ ac29e6f7-6d47-4b8f-9a3f-23691cefbfa7\%40sessionmgr11

Jacobs, J. E. (2005). Twenty-five years of research on gender and ethnic differences in math and science career choices: What have we learned? New Directions for Child and Adolescent Development, 2005(110), 85-94.

Jennings, J., \& Rentner, D. S. (2006). How public schools are impacted by "no child left behind". Education Digest, 72(4), 4-9.

Jones, S. M., \& Dindia, K. (2004). A meta-analytic perspective on sex equity in the classroom. Review of Educational Research, 74(4), 443-471. Retrieved on March 18, 2007 from http://0-www.jstor.org.helin.uri.edu/stable/pdfplus/3515978.pdf

Kahveci, A., Southerland, S. A., \& Gilmer, P. J. (2006). Retaining undergraduate women in science, mathematics, and engineering. Journal of College Science Teaching, 36(3), 34-38.

Kindlon, D., \& Thompson, M. (1999). Raising Cain: Protecting the emotional life of boys. New York: Ballentine books. 
Klein, S. S., Ortman, P. E., Campbell, P., Greenberg, S., Hollingsworth, S., Jacobs, J., Wiggins, J. (1994). Continuing the journey toward gender equity. Educational Researcher, 23(8), pp. 13-21. Retrieved on August 19, 2005 from http://0www.jstor.org.helin.uri.edu/stable/pdfplus/1176858.pdf

Koenker, R., \& Bassett Jr, G. (1978). Regression quantiles. Econometrica: Journal of the Econometric Society, 33-50.

Koenker, R., \& Hallock, K. F. (2001). Quantile regression. The Journal of Economic Perspectives, 15(4), pp. 143-156.

Koerselman, K. (2010). Admissible statistics of educational achievement scores. Investigaciones De Economía De La Educación Volume 5, 5, 781-796.

Kongar, E., Kontogiorgis, P., Russo, N. L., \& Sobh, T. M. (2009). Women in science, engineering and technology: Changing roles and perception within the technical services industries. Journal of Engineering and Applied Sciences, 4(1), 46-50.

Kuenzi, J. J. (2006). Science, technology, engineering, and mathematics (STEM) education issues and legislative options.

http://www.fas.org/sgp/crs/misc/RL33434.pdf

Ladd, H. F. (2012). Education and poverty: Confronting the evidence. Journal of Policy Analysis and Management,

Lankford, H., Loeb, S., \& Wyckoff, J. (2002). Teacher sorting and the plight of urban schools: A descriptive analysis. Educational Evaluation and Policy Analysis, 24(1), 37-62.

Leahy, E., \& Guo, G. (2001). Gender differences in mathematical trajectories. Soc.F., 80, 713. Retrieved on March 12, 2007 from http://0www.jstor.org.helin.uri.edu/stable/pdfplus/2675595.pdf

Leinhardt, G., Seewald, A. M., \& Engel, M. (1979). Learning what's taught: Sex differences in instruction. Journal of Educational Psychology, 71(4), 432. Retrieved August 15, 2005 from http://0web.ebscohost.com.helin.uri.edu/ehost/pdfviewer/pdfviewer?vid=3\&hid=24\&sid $=31 \mathrm{f} 90 \mathrm{f} 81-0 \mathrm{dd} 9-42 \mathrm{ef}-\mathrm{a} 63 \mathrm{e}-2 \mathrm{a} 9 \mathrm{bda} 20 \mathrm{~d} 3 \mathrm{c} 0 \% 40$ sessionmgr 13

Lowrie, T., \& Kay, R. (2001). Relationship between visual and nonvisual solution methods and difficulty in elementary mathematics. The Journal of Educational Research, 94(4), 248-255.

Lubienski, S. T., \& Lubienski, C. (2006). School sector and academic achievement: A multilevel analysis of NAEP mathematics data. American Educational Research Journal, 43(4), 651-698. 
Ma, L. (1999). Knowing and teaching elementary mathematics: Teachers' understanding of fundamental mathematics in china and the united states Lawrence Erlbaum Associates Mahwah, NJ.

Martin, A. J., \& Marsh, H. W. (2006). Academic resilience and its psychological and educational correlates: A construct validity approach. Psychology in the Schools, 43(3), 267-281.

http://www.eric.ed.gov/ERICWebPortal/search/detailmini.jsp? \&ERICExtSearch SearchValue 0=EJ761877\&ERICExtSearch_SearchType $0=$ no\&accno=EJ7618 $\underline{77}$

McGraw, R., Lubienski, S. T., \& Strutchens, M. E. (2006). A closer look at gender in NAEP mathematics achievement and affect data: Intersections with achievement, Race/Ethnicity, and socioeconomic status. Journal for Research in Mathematics Education, 37(2), 129-150. Retrieved on September 8, 2011 from http://0www.jstor.org.helin.uri.edu/stable/pdfplus/30034845.pdf

McLeod, D. B. (1992). Research on affect in mathematics education: A reconceptualization. Handbook of Research on Mathematics Teaching and Learning , 575-596.

McLoyd, V. C. (1998). Socioeconomic disadvantage and child development. American Psychologist, 53(2), 185-204.

Meece, J. L., Glienke, B. B., \& Burg, S. (2006). Gender and motivation. Journal of School Psychology, 44(5), 351-373.

Milar, K. S. (2000) The first generation of women psychologists and the psychology of women. American Psychologist, 55(6), 616--619. doi:10.1037/0003- 66X Retrieved on May 18, 2011 from http://0web.ebscohost.com.helin.uri.edu/ehost/pdfviewer/pdfviewer?vid=3\&hid=24\&sid $=80503834-5 \mathrm{f} 30-417 \mathrm{~d}-\mathrm{b} 1 \mathrm{e} 4-7474574 \mathrm{~b} 1 \mathrm{ae} 8 \% 40$ sessionmgr 11

Miller, J. D., \& Kimmel, L. G., (2010). Pathways to a STEMM career. Retrieved December 14, 2011 from http://news.msu.edu/media/documents/2010/02/79874644-d2cb-4def- 17fe67cc27b929d.pdf

National Assessment of Educational Progress (NAEP) (2008). The Nation's Report Card. Retrieved August 12, 2010 from http://nces.ed.gov/nationsreportcard/itmrls/startsearch.aspx

National Center for Educational Statistics (2004). Retrieved on April 3, 2008 from http://nces.ed.gov/. 
National Center for Education Statistics. Average mathematics scale score, by age and selected student and school characteristics: selected years, 1973 to 1999. Washington, D.C.: U.S. Department of Education, National Center for Education Statistics, 2003a. May 2, 2010 at http://nces.ed.gov/programs/digest/d03/tables/

National Council on Measurement in Education (1999). Standards for educational and psychological testing. Washington, DC: American Educational Research Association.

National Governor's Association, (2011) Building a science, technology, and math education agenda. NGA Center for Best Practices December 2011. retrieved April 12, 2011 from http://www.nga.org/files/live/sites/NGA/files/pdf/1112STEMGUIDE.PDF

National Science Foundation (2008). Science and Engineering Indicators 2008. Retrieved August 3, 2009, from http://www.nsf.gov/statistics/seind08/c0/c0i.htm

New Hampshire Department of Education, New England Common Assessment Technical Report. Retrieved October 18, 2012 from: http://www.education.nh.gov/instruction/assessment/necap/documents/techrpt jul y2011.pdf

Ornstein, P. (1995). Schoolgirls. New York: Anchor Books, Doubleday.

Payne-Tsoupros, C. (2010). No child left behind: Disincentives to focus instruction on students above the passing threshold. $J L \& E d u c ., 39,471$.

Penner, A. M., \& Paret, M. (2008). Gender differences in mathematics achievement: Exploring the early grades and the extremes. Social Science Research, 37(1), 239253.

Peterson, P. L., \& Fennema, E. (1985). Effective teaching, student engagement in classroom activities, and sex-related differences in learning mathematics. American Educational Research Journal, 22(3), 309-335. Retrieved on February 18, 2007 from http://0-www.jstor.org.helin.uri.edu/stable/10.2307/1162966

Pollack, W. (1998). Real boys: Rescuing our sons from the myths of boyhood. New York: Henry Holt and Company.

Prawat, R., \& Jarvis, R. (1980). Gender difference as a factor in teachers' perceptions of students. Journal of Educational Psychology, 72, 743-749. 
Rhode Island Department of Education, New England Common Assessment Technical Report. Retrieved from: . Retrieved October 28, 2011 from http://www.education.nh.gov/instruction/assessment/necap/documents/techrpt jul y2011.pdf

Sadker, M., \& Sadker, D. (1990). Confronting sexism in the college classroom Gender in the Classroom: Power and Pedagogy, , 176-187.

Sadker, M., Sadker, D., \& Klein, S. (1991). The issue of gender in elementary and secondary education. Review of Research in Education, 17, pp. 269-334.

Retrieved August 2, 2005 from http://0-

www.jstor.org.helin.uri.edu/stable/pdfplus/1167334.pdf

Schoen, H. L., Cebulla, K. J., Finn, K. F., \& Fi, C. (2003). Teacher variables that relate to student achievement when using a standards-based curriculum. Journal for Research in Mathematics Education, , 228-259

Schreiber, J. B. (2002). Institutional and student factors and their influence on advanced mathematics achievement. The Journal of Educational Research, 95(5), 274-286. Retrieved on August 15, 2011 from http://0www.jstor.org.helin.uri.edu/stable/pdfplus/27542390.pdf

Schunk, D. H. (1981). Modeling and attributional effects on children's achievement: A self-efficacy analysis. Journal of Educational Psychology, 73(1), 93-105.

Schunk, D. H. (1984). Self-efficacy perspective on achievement behavior. Educational Psychologist, 19(1), 48-58. .

Vermeer, H. J., Boekaerts, M., \& Seegers, G. (2000). Motivational and gender differences: Sixth-grade students' mathematical problem-solving behavior. Journal of Educational Psychology, 92(2), 308-15. Retrieved November 10, 2006 from http://0web.ebscohost.com.helin.uri.edu/ehost/pdfviewer/pdfviewer?vid=3 $\underline{\text { \&hid }=8 \& \mathrm{sid}=2 \mathrm{c} 507 \mathrm{ff} 0-83 \mathrm{f} 9-46 \mathrm{c} 4-8 \mathrm{e} 72-\mathrm{bc} 519 \mathrm{a} 24 \mathrm{f} 8 \mathrm{~b} 5 \% 40 \text { sessionmgr } 13}$

Seegers, G., \& Boekaerts, M. (1996). Gender-related differences in selfreferencedcognitions in relation to mathematics. Journal for Research in Mathematics Education, 27(2), 215-240. Retrieved on March 20, 2007 from http://0-www.jstor.org.helin.uri.edu/stable/pdfplus/749601.pdf?acceptTC $=$ true

Sells, L. W. (1973). High school mathematics as the critical filter in the job market. Developing Opportunities for Minorities in Graduate Education, 37-39.

Retrieved June 4, 2010 from http://www.eric.ed.gov/ERICWebPortal/search/detailmini.jsp? nfpb=true\& \&ER ICExtSearch SearchValue 0=ED080351\&ERICExtSearch_SearchType 0=no\&a $\underline{\mathrm{ccno}=\mathrm{ED} 080351}$ 
Shields, S. (1975). Functionalism, darwinism, and the psychology of women. American Psychologist, 30(7), 739-739-754. doi: 10.1037/h0076948 Retrieved on July 1, 2011 from http://www.la6.psu.edu/psychwww /research/shields/home/resources/Shields 1975.pdf

Siegel, D., \& McCoach, D. (2007). Increasing student mathematics self-efficacy through teacher training. Journal of Advanced Academics, 18(2), 278-312.

Silver, E., \& Thompson, A. (1984). Research perspectives on problem solving in elementary school mathematics. The Elementary School Journal, 84, 529-545.

Sirin, S. R. (2005). Socioeconomic status and academic achievement: A meta-analytic review of research. Review of Educational Research, 75(3), pp. 417-453.

Sommers, C. (2000). The War Against Boys. Atlantic Monthly, 285, 59-74. Retrieved August 18, 2000, from http://www.theatlantic.com/past/issues/2000/05/sommers.htm

Steen, L. A. (1987). Mathematics education: A predictor of scientific competitiveness. Science, 237(4812), 251-52,302. Retrieved on May 5, 2011 from http://www.sciencemag.org/content/237/4812/251.full.pdf?sid=af9ecaf6-9819$\underline{4425-\mathrm{a} 118-33 \mathrm{bc} 338271 \mathrm{e} 0}$

Stipek, D., \& Gralinski, H. (1991) Gender differences in children's achievementrelated beliefs and emotional responses to success and failure in mathematics. Journal of Educational Psychology, 83, 361-371. Retrieved March 4, 2005 from http://0web.ebscohost.com.helin.uri.edu/ehost/pdfviewer/pdfviewer?vid=3\&hid= 19\&sid=47bab1 ad-1204-46c0-8b60-52454a5f4990\%40sessionmgr4

Tai, R. H., Liu, C. Q., Maltese, A. V., \& Fan, X. (2006). Planning early for careers in science. Life Sci, 1, 0.2.

Tetreault, M., (1986). The journey from male-defined to gender-balanced education. Theory into Practice, 25, 227-34.

Thompson, H. B. (1903). The mental traits of sex. Chicago: University of Chicago Press. Retrieved June, 22, 2005 from http://archive.org/stream/cu31924029178675\#page/n5/mode/2up

Toulmin, C. N., \& Groome, M. (2007). Building a science, technology, engineering, and math agenda. National Governors Association, 32.

Tsai, S., \& Walberg, H. J., (1983). Mathematics achievement and attitude productivity in junior high school. Journal of Educational Research, 76, 267-272. Retrieved August 5, 2010 from http://0 www.jstor.org.helin.uri.edu/stable/pdfplus/27539985.pdf 
Tyack, D. B., \& Hansot, E. (1992). Learning together: A history of gender in american public schools. New York: Russell Sage Foundation.

United States Department of Agriculture, food and nutrition service, Income eligibility guidelines Retrieved April 8, 2012 from http://www.fns.usda.gov/cnd/governance/notices/iegs/iegs.htm

United States Census Bureau. (2010). Retrieved April 19, 2012 from http://2010.census.gov/2010census/

United States Department of Education (2004). The nation's report card. National Center for Educational Statistics. Retrieved February 10, 2008 from http://nces.ed.gov/pubs2005/equity/Section4.asp

United States. Dept. of Education, \& United States. National Advisory Council on Women's Educational Programs. (1981). Title IX: The half full, half empty glass. Retrieved February 8, 2011 from http://www.eric.ed.gov/ERICWebPortal/search/detailmini.jsp?_nfpb=true\&_\&ER ICExtSearch SearchValue 0=ED209152\&ERICExtSearch_SearchType 0=no\&a $\underline{\mathrm{ccno}=\mathrm{ED} 209152}$

United States Department of Labor. Employment and Training Administration. (2007). The STEM workforce challenge: the role of the public workforce system in a national solution for a competitive science, technology, engineering, and mathematics (STEM) workforce. Retrieved November 18, 2011 from http://www.doleta.gov/Youth services/pdf/STEM Report 4\%2007.pdf

Vanneman, A., Hamilton, L., Anderson, J. B., Rahman, T., \& National Center for, E. S. (2009). Achievement gaps: How black and white students in public schools perform in mathematics and reading on the national assessment of educational progress. statistical analysis report. NCES 2009-455.National Center for Education Statistics.

Vermeer, H. J., Boekaerts, M., \& Seegers, G. (2000). Motivational and gender differences: Sixth-grade students' mathematical problem-solving behavior. Journal of Educational Psychology, 92(2), 308. Retrieved March 8, 2005 from http://0-content.ebscohost.com.helin.uri.edu/pdf19_22/pdf/ddd/pdh/edu/edu-92-2308.pdf? $=\mathrm{P} \& \mathrm{P}=\mathrm{AN} \& \mathrm{~K}=2000-07799007 \& \mathrm{~S}=\mathrm{L} \& \mathrm{D}=\mathrm{pdh} \& E b s c o$ Content $=$ dGJyMNHr7ESeprI4zOX0OLCmr0qep7dSrq64TLSWxWXS\&ContentCustomer $=$ dGJyMPGut0\%2B2qrVNuePfgeyx44Dt6fIA

Wayne, A. J., \& Youngs, P. (2003). Teacher characteristics and student achievement gains: A review. Review of Educational Research, 73(1), 89-122. 
Weaver-Hightower, M. (2003). The "boy turn" in research on gender and education. Review of Educational Research, 73(4), 471-498. Retrieved August 1, 2005 from http://0-rer.sagepub.com.helin.uri.edu/content/73/4/471.full.pdf

Wehmeyer, M. L., \& Schwartz, M. (2001). Disproportionate representation of males in special education services: Biology, behavior, or bias?. Education and Treatment of Children, 24(1), 28-45.

Weiner, B. (1994). Integrating social and personal theories of achievement striving. Review of Educational Research, 64 (4), 557-573.

White, K. R. (1982). The relation between socioeconomic status and academic achievement. Psychological Bulletin, 91(3), 461-81.

Whitehouse.gov. (2012) Educate to Innovate. Retrieved August 12, 2012, from http://www.whitehouse.gov/issues/education/k-12/educate-innovate

Woolley, H. T.A, (1910). review of the recent literature on the psychology of sex. Psychological Bulletin, 7, 335-342. Retrieved August 2011 from http://psychclassics.yorku.ca/Thompson/psychsex.htm

Xie, Y., \& Shauman, K. A. (2003). Women in science: Career processes and outcomes Harvard University Press Cambridge, MA 